Universidade de Brasília

Centro de Excelência em Turismo - CET

Pós-graduação Lato Sensu

Especialização em Turismo e Desenvolvimento Econômico

\title{
CENÁRIOS PROSPECTIVOS E O DESENVOLVIMENTO DO TURISMO: ASPECTOS TEÓRICOS E OPERACIONAIS
}

Marta Cristine Peres Barros

Orientador: Prof. Dr. Jorge Madeira Nogueira 
Universidade de Brasília

Centro de Excelência em Turismo - CET

Pós-graduação Lato Sensu

Especialização em Turismo e Desenvolvimento Econômico

Marta Cristine Peres Barros

Aprovado por:

Orientador: Prof. Dr. Jorge Madeira Nogueira

Professor: Antonio Nascimento Junior

Professora: Dr ${ }^{\text {a }}$.Maria de Lourdes Mollo

Brasília, 09 de março de 2008. 


\section{DEDICATÓRIA}

Dedico este trabalho a duas pessoas em especial:

à minha filha Ana Carolina que sempre apoiou minhas escolhas e ao meu querido orientador Jorge Nogueira que me conduziu brilhantemente na busca do conhecimento e me incentivou para a conclusão deste trabalho. 


\section{RESUMO}

Uma série de fenômenos de caráter social, econômico e tecnológico está acontecendo em todo o mundo. A transformação da economia mundial, as novas funções exigidas da administração pública e a proliferação de novos produtos e serviços no mercado globalizado, estão impondo cenários em constante transformação, impactando os sistemas tradicionais de gestão e exigindo a busca de novas ações estruturais e operacionais.

Na percepção mais ampla de uma organização, pode-se afirmar que o universo de variáveis endógenas e exógenas ligadas a um sistema de gestão produz os mais diversos desafios. Compreender esses desafios e tentar vencê-los é o papel das organizações em situações e momentos diferentes utilizando-se de instrumentos que emprestam a melhor contribuição para cada caso. Dentre os possíveis caminhos para um diagnóstico de uma situação, uma análise de cenários prospectivos é uma ferramenta que auxilia no tratamento das variáveis de forma estratégica.

Um dos problemas apontados no turismo brasileiro é a falta de posicionamento no mercado e de visão estratégica do setor. Para corrigir isso, o esforço tem demandado estudos e levantamento do potencial regional a partir do desenvolvimento de planejamento estratégico. No entanto é preciso realizar um estudo detalhado das variáveis e atores que entram na escala de produção do setor para então traçar cenários futuros com a redução de riscos e incertezas.

Neste contexto o pensamento estratégico estimula à visão sistêmica e global do mundo, permitindo um diagnóstico que permita tomar decisões e permear ações que garantam o desenvolvimento econômico, equidade sociedade e preservação da identidade e cultura do país e suas regiões.

Os métodos e técnicas em cenários certamente não resolvem todas as demandas e anseios das organizações empresariais, governamentais e da sociedade, porém podem contribuir com o processo de aprendizagem e crescimento nos níveis sistêmicos que envolvem situações repletas de incertezas.

O modelo aqui proposto oferece uma alternativa metodológica que prescinde de investimentos e esforços técnicos na produção de cenários prospectivos que gerem projetos para promover o desenvolvimento do turismo regional. 


\section{SUMÁRIO}

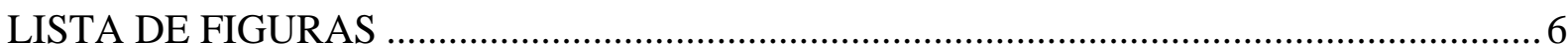

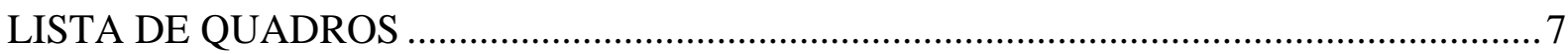

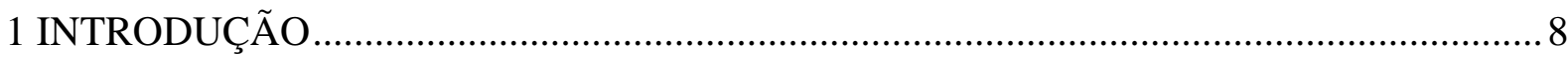

2 CENÁRIOS PROSPECTIVOS: ADIVINHAR OU ANTECIPAR? .....................................13

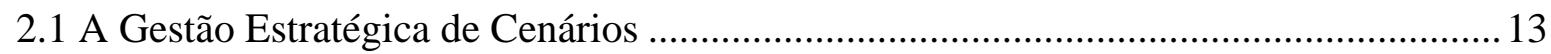

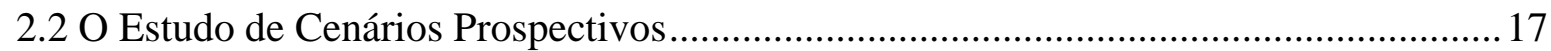

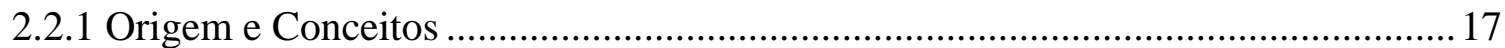

2.2.2 Cenários Prospectivos: Características, Enfoques e Tipologia. ............................... 21

2.2.3 Técnicas e Métodos de elaboração de análise de cenários prospectivos..................23

3 MÉTODOS PARA A CONSTRUÇÃO DE CENÁRIOS PROSPECTIVOS ....................... 26

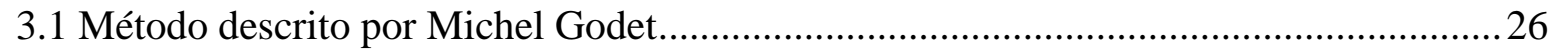

3.2 Método Descrito por Peter Schwartz ou da Global Busines Network (GBN) ...............28

3.3 Método de Cenários Industriais de Michael Porter ........................................................ 31

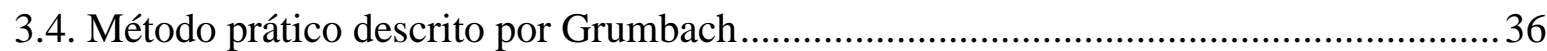

4 A EXPERIÊNCIA BRASILEIRA COM CENÁRIOS PROSPECTIVOS ............................ 41

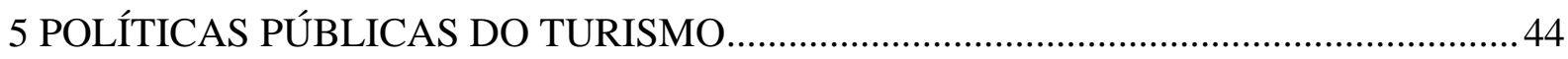

5.1 O Programa de Regionalização do Turismo - Roteiros do Brasil................................. 44

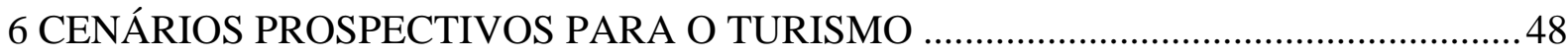

6.1 Proposta de um Referencial Metodológico Teórico para Construção de Cenários

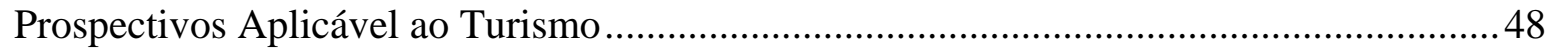

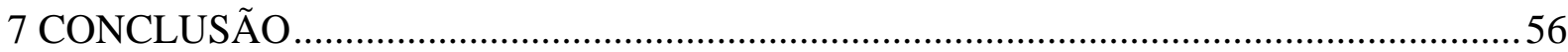

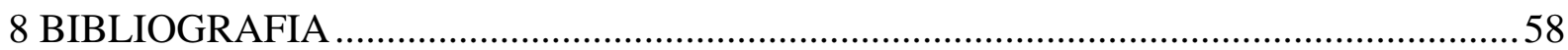




\section{LISTA DE FIGURAS}

Figura 1 - A Organização e o Sistema de Gestão ...............................................................

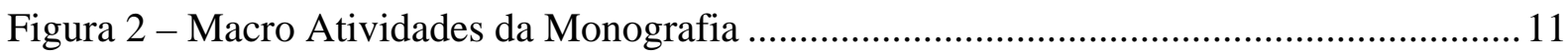

Figura 2 - Roteiro de Determinação de Estratégias .............................................................. 15

Figura 3 - Roteiro de Decisões Estratégicas ....................................................................... 16

Figura 4 - Fases do Método Descrito por Godet ................................................................... 26

Figura 05 - Fases do Método Descrito por Peter Schwartz ….................................................. 28

Figura 06 - Fases do Método descrito por Michel Porter .......................................................... 31

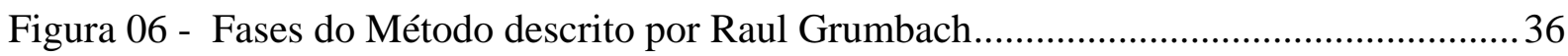

Figura 7 - Módulos Operacionais do Programa de Regionalização do Turismo ...................... 45

Figura 8 - Etapas do Método Proposto para Geração de Cenários no Turismo........................ 49

Figura 9 - Matriz de Análise Estrutural - variável/variável ................................................. 50

Figura 10 - Diagrama motrocidade-dependência.................................................................. 51

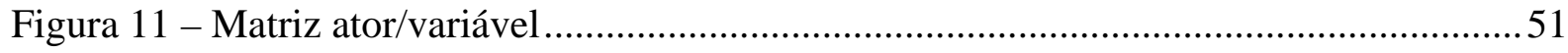

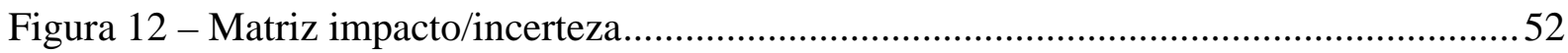

Figura 13 - Matriz de Investigação Morfológica ............................................................... 54 


\section{LISTA DE QUADROS}

Quadro 1- Etapas para definição de ações estratégicas ......................................................... 14

Quadro 2 - Etapas do Método Michel Godet ....................................................................... 27

Quadro 3 - Etapas do Método Peter Schwartz ou da Global Busines Network (GBN)........... 30

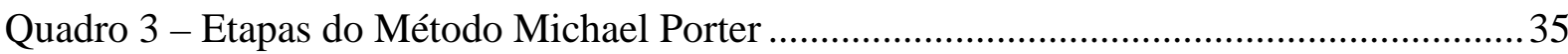

Quadro 4 - Fases do Método descrito por Grumbach .............................................................. 40 


\section{INTRODUÇÃO}

O contexto do mundo globalizado tem exigido das organizações novas formas de pensar e agir face à rápida mudança tecnológica, de mercados, consumidores, sociedade e governo. Essas mudanças também têm alterado as configurações das variáveis internas e externas das empresas, tais como: questões sociais, econômicas, políticas, ambientais, demográficas e governamentais e, consequentemente, gerando situações com alto grau de complexidade e imprevisibilidade. Para vencer esses obstáculos torna-se imprescindível a busca de alternativas que nos permita interpretar e planejar situações futuras.

O planejamento consiste em um processo administrativo onde se estabelecem os objetivos ou metas organizacionais e os melhores meios de como alcançá-los por meio da organização dos recursos disponíveis. É tida como a primeira função administrativa devido a sua tamanha importância de envolver a solução de problemas e a tomada de decisões não só quanto às alternativas futuras, mas também às alternativas do presente (Chiavenato, 2004).

É neste momento que toda organização se insere em um sistema de gestão, e conforme apresentado por Aluísio Guimarães e Claudio Porto (2002), à medida que o contexto externo sofre mudanças, todo o quadro interno da organização é afetado em diversos graus de extensão e profundidade. Desta forma o sistema de gestão contribui para uma melhor compreensão de suas características e das restrições às quais é submetido.

Conforme figura 1, os mesmos autores detalham ainda que de um lado, existem os elementos internos da organização que o contém, tais como o modelo estrutural, o clima, a cultura e a natureza do trabalho organizacional, bem como os demais sistemas organizacionais (tecnológico, de planejamento, de recursos humanos, de informação e administrativos). De outro lado, há diversos sistemas e entidades pertencentes ao ambiente da organização que, de um modo geral, têm influência decisiva na sua gestão. Tudo isso encontra-se submetido, por sua vez, a um conjunto de forças e fatores que atuam no sistema social mais amplo em que a organização está situada. 
Figura 1 - A Organização e o Sistema de Gestão

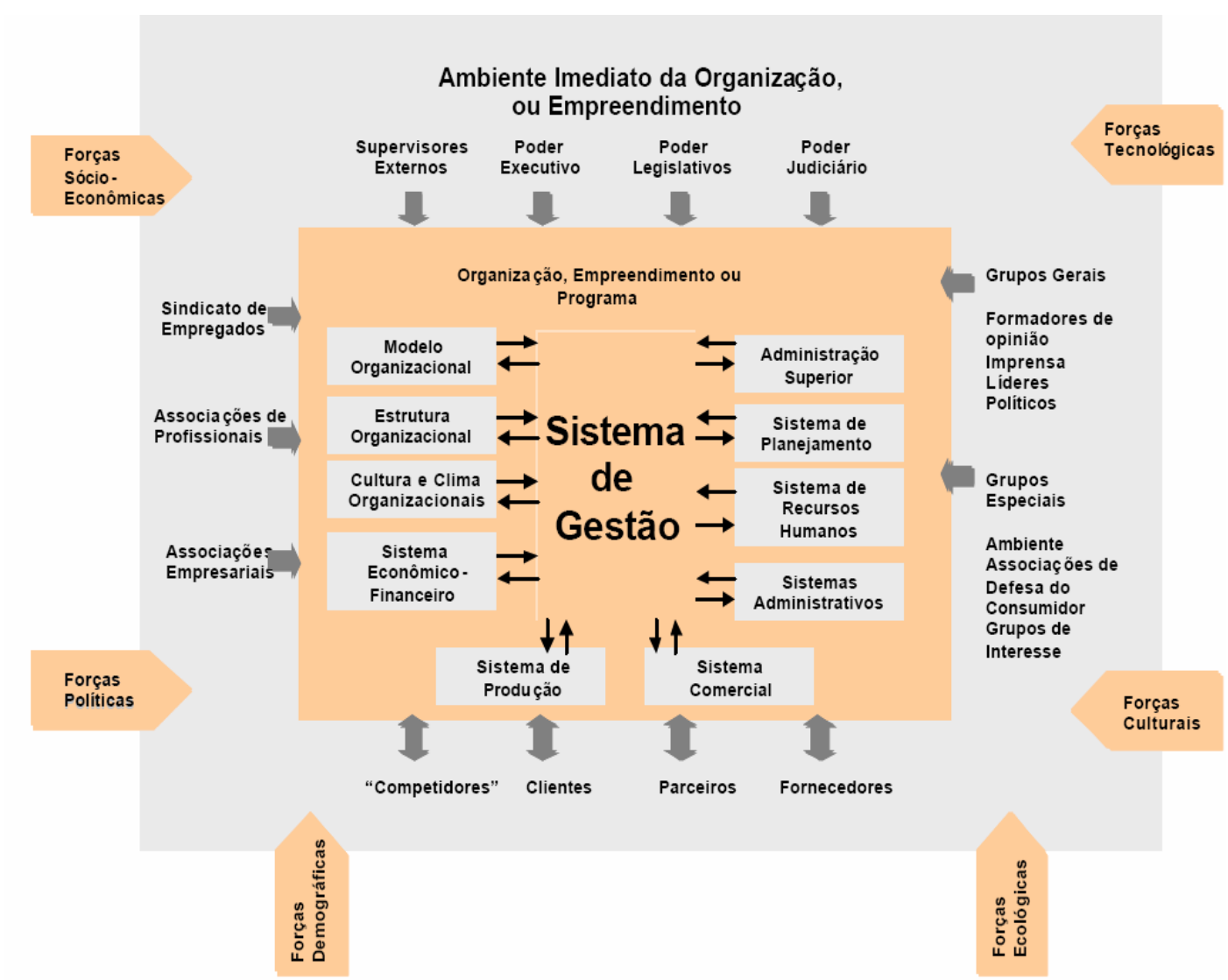

Fonte: Macroplan 2002

Em particular, o planejamento turístico deve, entre outros objetivos, maximizar os benefícios sócio-econômicos e minimizar os custos, visando o bem estar da comunidade receptora e a rentabilidade dos empreendimentos do setor.

A atividade turística possui como a maior parte das atividades econômicas e sociais, a capacidade de promover impactos de ordem positiva e negativa. È baseado nisto que, diversos estudiosos vêm se preocupando em tornar pública a importância da preservação e do planejamento, de forma concreta e permanente.

A grande expansão em escala mundial do turismo aponta o setor como impulsionador para o desenvolvimento econômico. A atividade turística utiliza bens naturais; emprega grande quantidade e diversidade de mão-de-obra; gera rendas individuais e empresariais; proporciona o ingresso de divisas na balança de pagamentos; origina receitas para os cofres públicos; produz múltiplos efeitos na economia do país, valoriza imóveis e impulsiona a construção civil. 
Os resultados do movimento financeiro decorrentes do turismo são expressivos e justificam a preocupação de governos e entidades na busca pelo fortalecimento do setor com estratégias que garantam o crescimento sustentável.

Esse processo gera mudanças nos ambientes organizacionais que buscam adaptar-se às demandas e necessidades geradas pelo setor. Todas essas forças estão exigindo das organizações preocupação e renovação do seu planejamento de longo prazo e a necessidade de utilizarem as técnicas de Cenários Prospectivos para melhor identificar as forças dinâmicas que prevalecerão nos próximos anos.

A partir das incertezas geradas neste contexto as técnicas de cenários prospectivos, ao serem introduzidas nas organizações, podem produzir um efeito multiplicador na gestão estratégica e nos seus desdobramentos futuros, pois transferem para cultura da empresa a arte de criar e imaginar o futuro, facilitando a trajetória da mesma em seu ambiente de negócios competitivo.

Os estudos prospectivos não têm como objetivo prever o futuro, mas estudar as diversas possibilidades de futuros plausíveis existentes e preparar as organizações para enfrentá-las, ou até mesmo criar condições para que modifiquem as probabilidades de ocorrência de situações incertas, ou minimizar seus efeitos. Na percepção mais ampla de uma organização, pode-se afirmar que o universo de variáveis produz os mais diversos desafios. Compreender esses desafios e tentar vencê-los é o papel das organizações em situações e momentos diferentes.

Dentre os possíveis caminhos para um diagnóstico e análise de diferentes possibilidades de ocorrência de um determinado evento, uma análise de cenários prospectivos é um dos instrumentos a ser utilizado, ou como tratam alguns autores, como sendo uma ferramenta que auxilia no tratamento das variáveis de forma estratégica. Essas situações de complexidades e imprevisibilidade exigem das empresas e dos seus administradores, novas habilidades gerenciais, no sentido de melhor interpretá-las e planejá-las, nas suas conseqüências futuras para as organizações. Dentre elas encontram-se não só o conhecer e o planejar o longo prazo, mas em especial, implantar o estudo de cenários prospectivos ou a arte da visão de longo prazo nas modernas organizações.

Diante do exposto, a presente monografia tem como pergunta de pesquisa a seguinte indagação central: Como a metodologia de Análise de Cenários Prospectivos poderá contribuir para a construção de um referencial metodológico, de planejamento que possa ser utilizado pelas organizações do setor turístico? 
A pesquisa e o desenvolvimento deste trabalho foi dividido em quatro macro atividades, conforme delineado no figura 2 abaixo. Na primeira etapa foi realizada uma pesquisa secundária junto à literatura especializada com vistas a levantar o a origem dos cenários prospectivos no ambiente da ação estratégica. Na segunda etapa foi realizado um estudo analítico dos principais modelos e técnicas de geração de cenários; em seguida uma análise do Plano Nacional do Turismo e do Programa de Regionalização adotado pelo Ministério do Turismo no que tange ao desenvolvimento regional do turismo, finalizando com a elaboração da proposta de um referencial teórico e metodológico de análise prospectiva para aplicação no setor turístico.

Figura 2 - Macro Atividades

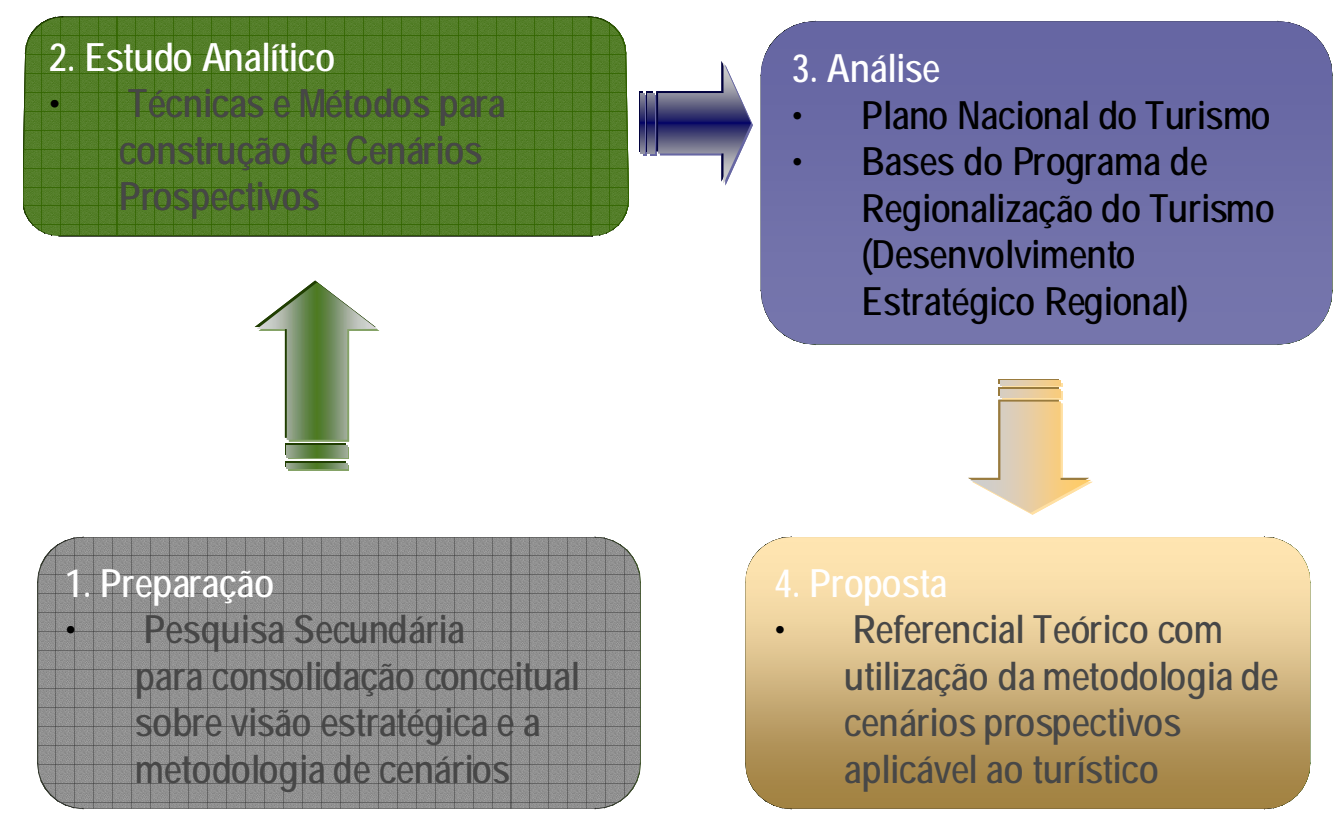

Fonte: elaborado pela autora

Neste contexto o presente trabalho está distribuído em oito seções. Como introdução ao assunto, apresento a contextualização da importância do planejamento para a atividade turística no Brasil percebida atualmente por meio dos crescentes e expressivos resultados na economia nacional e as constantes mudanças provocadas nos diversos ambientes organizacionais. Na Seção 2, citam-se os conceitos ligados à gestão estratégica, origem dos estudos em cenários prospectivos, características, enfoques e tipologias e técnicas auxiliares. Em seguida está descrito os métodos desenvolvidos pelos principais autores que são tidos como referência mundial no assunto com base conceitual, filosofia e passos bem definidos. 
Na Seção 4, realiza-se um levantamento da experiência brasileira com cenários prospectivos de forma cronológica onde cito algumas instituições que desenvolveram estudos utilizando a metodologia de cenários prospectivos como orientação para definição e aplicação de estratégias com vistas ao crescimento dos objetos em estudo. Na seção 5, é apresentado a atual política pública adotada pelo Ministério do Turismo, em especial, ao Programa de Regionalização do Turismo que trata da elaboração do Plano Estratégico de Desenvolvimento do Turismo Regional, sua metodologia e aspectos relevantes.

Na Seção 6, apresento a proposta do referencial metodológico teórico para construção de cenários prospectivos aplicáveis ao turismo composta de 5 etapas que visam diminuir as incertezas em relação ao futuro quando na decisão de projetos e investimentos no setor.

Na conclusão deste trabalho é apresentado os aspectos positivos da utilização do referencial teórico metodológico para a construção de cenários prospectivos aplicáveis ao setor turístico. 


\section{CENÁRIOS PROSPECTIVOS: ADIVINHAR OU ANTECIPAR?}

\subsection{A Gestão Estratégica de Cenários}

Estratégia trata-se de um processo que visa integrar o conjunto de atividades de uma empresa e o sucesso depende de se conseguir fazer bem muitas coisas e saber integrá-las buscando construir um potencial de sucesso por meio das suas vantagens competitivas. Essa definição classificada por Porter (1992), sugere que a formulação e implementação de estratégias empresariais são um processo de gestão visando à tomada de decisão a médio e longo prazos, relativa à definição de negócios, objetivos de desenvolvimento e, muito em especial, a fatores-chave de sucesso. A essas decisões, pelo seu caráter duradouro e pelo que representam no relacionamento futuro da empresa com o seu meio envolvente, atribui-se o caráter de decisões estratégicas.

Para um determinado mercado, as decisões são tomadas, numa primeira fase, por meio do processo de formulação da estratégia. A análise SWOT (Identificação de pontos fortes, pontos fracos, ameaças e oportunidades), pode trazer à organização que a utiliza um conjunto de informações importantes para a tomada de decisões. Esse processo envolve: uma fase prévia destinada a identificar ameaças e oportunidades que o meio envolvente pode trazer à empresa, no presente e/ou no futuro (o Diagnóstico Externo); a identificação dos pontos fortes e fracos que a empresa revela, quando comparada com a concorrência (o Diagnóstico Interno).

As conclusões retiradas destes diagnósticos vão condicionar as fases seguintes do processo: segmentação do mercado; análise dos segmentos do mercado; escolha dos segmentos-alvo que a empresa pretende atacar; definição da ação comercial a implementar nesses segmentos e definição dos objetivos de desenvolvimento a atingir.

Bethlem (2002) afirma que a transformação de idéias “estratégicas” em ações “estratégicas” proporciona aos estrategistas os resultados que eles almejam. Conforme quadro 1 o processo se inicia com a elaboração do planejamento estratégico que com a consolidação e aceite das propostas geradas pelo grupo gera-se a plano estratégico que resulta na concretização e finalização das ações propostas. 


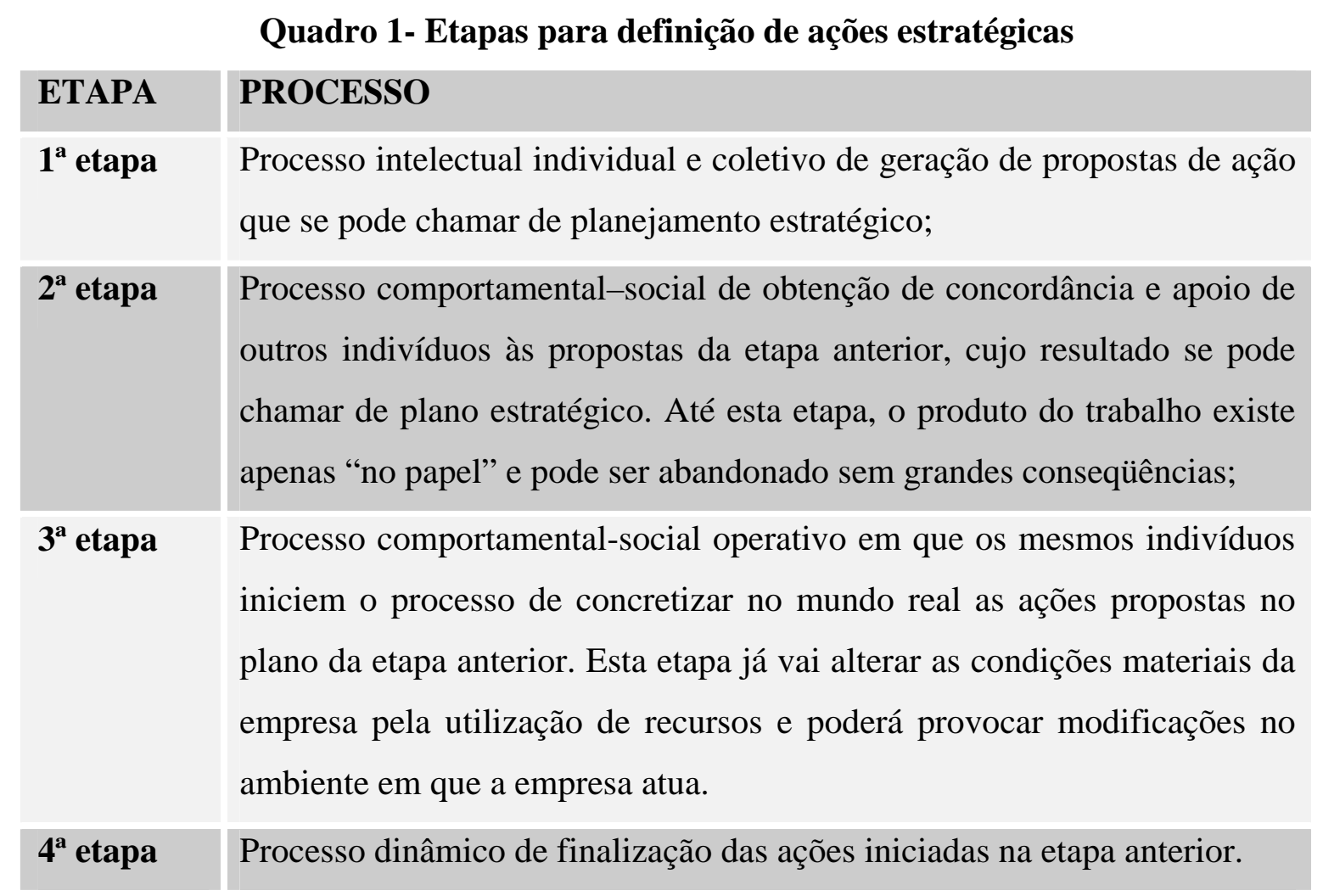

Fonte: Bethlem (2002)

O mesmo autor ainda apresenta um roteiro de auto-análise para determinação de estratégias conforme exposto a seguir na figura 2, que passa pela:

a) Visão da situação atual: O que a empresa é? O que a empresa faz? Como a empresa está? Onde a empresa está?

b) Cenários: O que vem por aí? Como vai afetar a empresa?

c) Com base nas respostas obtidas traçam-se as decisões estratégicas: O que a empresa será? O que a empresa fará? Como e onde a empresa estará?

d) Com o intuito de ajustar possíveis gaps, procedem-se às mesmas perguntas para readequação das decisões estratégicas que definiram o futuro desejado. 
Figura 2 - Roteiro de Determinação de Estratégias

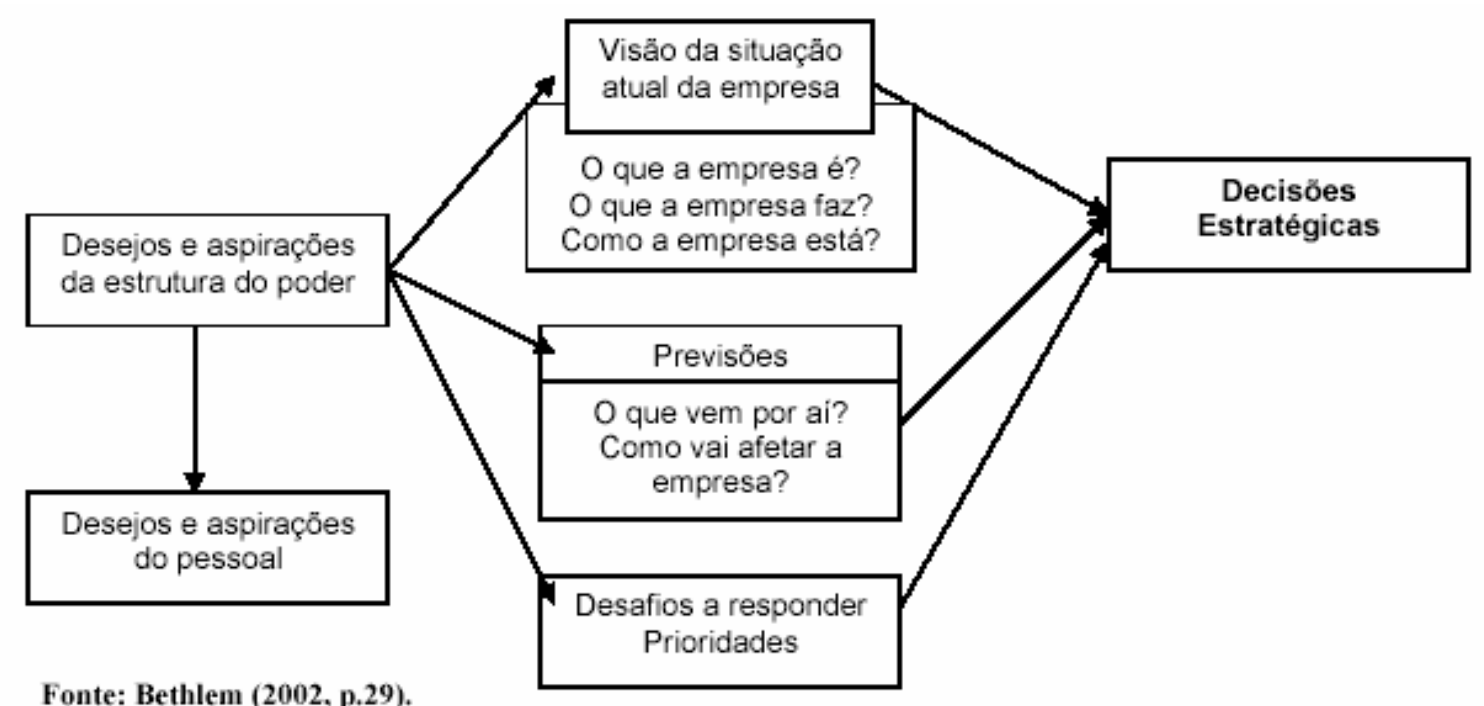

Da resposta aos questionamentos anteriores surgem as prioridades e os desafios a responder e as decisões estratégicas que vão fixar o futuro da organização. Esse conjunto define o futuro prospectado e/ou desejado pela estrutura de poder da organização. Será necessário um reexame mais detalhado das condições ambientais e dos recursos disponíveis, que produzirão as diferenças entre o exeqüível e o desejável. Tais diferenças são denominadas brechas ou hiatos. As possibilidades de redução ou fechamento dessas brechas devem ser examinadas cuidadosamente, para se obter o futuro esperado.

Reexaminando recursos e circunstâncias, chega-se às estratégias adotadas, sempre sujeitas a reexame e modificações, devido à condição mutável dos elementos analisados ou considerados. Ainda de acordo com Bethlem (2002), a figura 3 retrata os procedimentos mais utilizados no campo das decisões estratégicas nas organizações: 
Figura 3 - Roteiro de Decisões Estratégicas

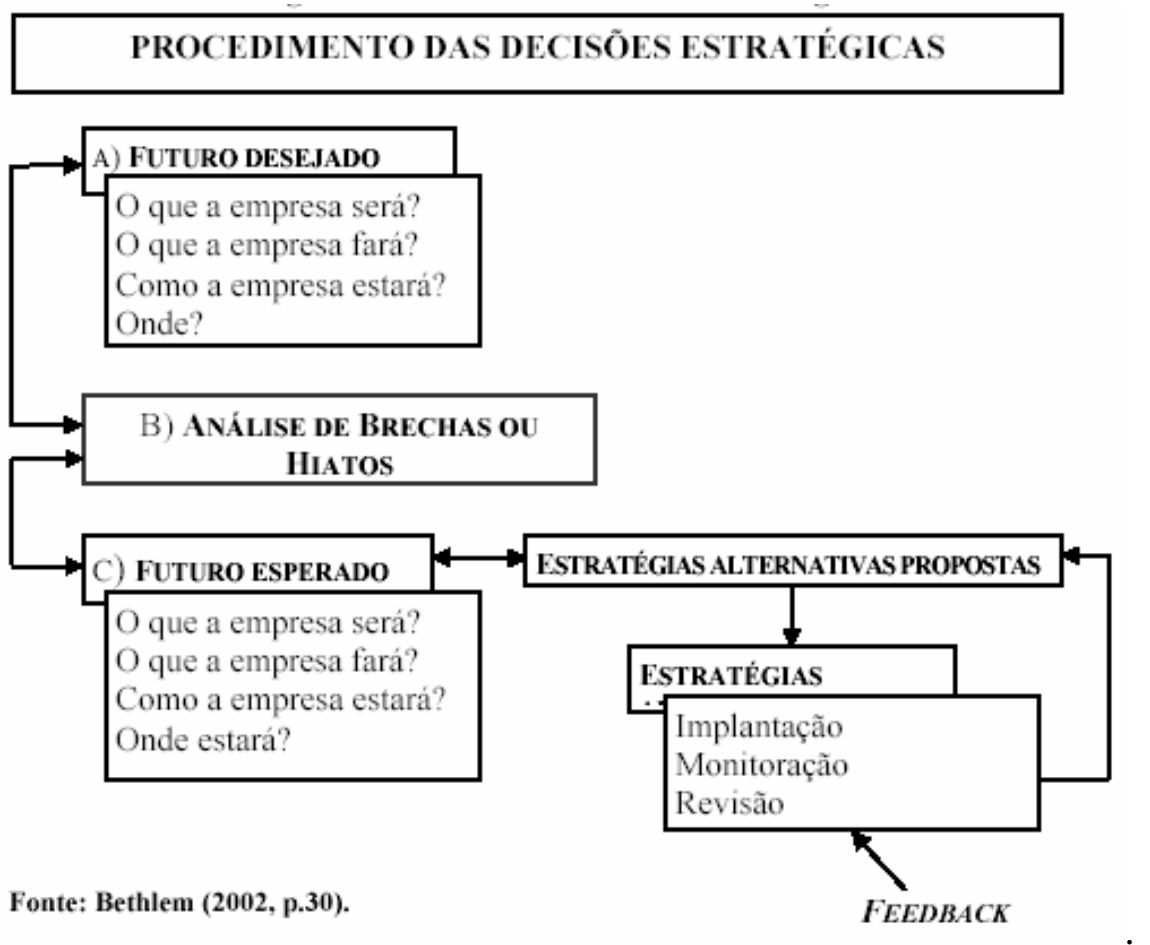

Na concepção de Henderson apud Montgomery \& Porter (1998, p. 5), "Estratégia é a busca deliberada de um plano de ação para desenvolver e ajustar a vantagem competitiva de uma empresa”. O autor desenvolve ainda, em seu estudo, os elementos básicos da competição estratégica:

(1) Capacidade de compreender o comportamento competitivo como um sistema no qual competidores, clientes, dinheiro, pessoas e recursos interagem continuamente;

(2) Capacidade de usar essa compreensão para predizer como um dado movimento estratégico vai alterar o equilíbrio competitivo;

(3) Recursos que possam ser permanentemente investidos em novos usos mesmo se os benefícios conseqüentes só aparecerem a longo prazo;

(4) Capacidade de prever riscos e lucros com exatidão e certeza suficientes para justificar o investimento correspondente;

(5) Disposição de agir.

De forma complementar Rebouças (1988, pg. 161) esclarece que o estabelecimento de estratégias é o resultado de uma análise interativa entre os fatores externos ou não controláveis e os fatores internos ou controláveis da empresa. 
No que diz respeito à análise dos fatores externos, o mesmo autor, aponta a utilização da técnica de cenários, como instrumento importante nesta análise, uma vez que, proporcionam os critérios e as medidas para preparação do futuro da empresa.

Sendo assim, a empresa obtém do ambiente as informações para que, com seu conhecimento prévio e com criatividade, possa desenvolver novos valores (soluções e tecnologia) de modo a manter ou ampliar sua posição no mercado, estabelecendo uma vantagem competitiva. O resultado deste processo é um conjunto de estratégias (projetos) a serem executadas pela empresa.

Nesse sentido, os rumos da estratégia atualmente devem estar muito mais voltados para o futuro do que para o presente. A estratégia, portanto, volta-se para o futuro buscando não só delineá-lo, mas, também, preparar as instituições para poderem atuar futuramente, competindo e obtendo sucesso.

\subsection{O Estudo de Cenários Prospectivos}

\subsubsection{Origem e Conceitos}

“Análise de Cenários é uma ferramenta para nos ajudar a adotar uma visão de longo prazo (com arte e criatividade), combinado com a prática da conversação estratégica, num mundo de grande incerteza política, social, econômica e tecnológica."

Peter Schwartz - Presidente da Global Business Network.

Desde muito tempo o homem tem sentido a necessidade de fazer uma prospecção do seu futuro, investigando quais as variáveis envolvidas, sejam elas relacionadas aos seus projetos dos diferentes níveis de interesse, ou seja, pessoal ou profissional, em todos os planos onde poderia atuar de forma direta ou indireta. De maneira geral a prospecção era feita de forma especulativa, sem parâmetros pré-determinados, não existindo uma sistematização dos dados a serem avaliados e quais procedimentos poderiam ser adotados em situações diferentes.

De acordo com Branco (2005), nos povos antigos a existência de oráculos é fartemente documentada na história, da China, na Dinastia Shang, de 1766 a.C., onde começou a ser utilizado o "I Ching", como forma de adivinhação ou de previsão de eventos futuros. E 
segundo Silva (2005), no antigo Egito as referências Bíblicas a inúmeros profetas, entre eles Jeremias, que viveu no período de 627 a.C. e 580 a.C.

Segundo Randow (2005), na Grécia o oráculo de Delphos é com certeza o mais famosos, onde não só os governantes gregos, mas de outras nações e pessoas comuns para lá se dirigiam para ouvir, antes de iniciar qualquer atividade de maior risco, o conselho das pitonisas, que faziam suas profecias, em um Templo dedicado a Apolo, onde estava escrito em seu frontispício "Ó homem, conhece-te a ti mesmo e conhecerás o Universo e os Deuses". Na seqüência da evolução humana esta necessidade permaneceu e o próprio oráculo de Delphos continuou a ter grande influência no Império Romano onde até hoje existe o Método Delphi de adivinhação ou de prospecção, utilizado por muitas empresas, organizações e governos.

A palavra "prospectiva" foi utilizada pela primeira vez pelo filósofo, economista e pedagogo francês Gaston Berger em sua obra A Atitude Prospectiva, de 1957, estabelecendo como descrever um futuro desejável para o mundo, definida como: olhar para o futuro, preocupar-se com o longo prazo; e ter cuidado com as interações, visando encontrar os fatores e tendências que são realmente importantes; considerando o gênero humano como agente capaz de modificar o futuro. No campo da visão prospectiva, há várias definições, que diferem na forma e na amplitude, mas que obedecem ao fundamento básico da prospectiva os futuros são múltiplos e incertos.

O termo “cenário”, embora apresente muitos significados, deriva do termo teatral grego “cenário”, que quer dizer o roteiro de uma peça de teatro. Os elementos principais para a conceituação e o entendimento da técnica são os mesmos do teatro moderno, quais sejam: cenários, cenas trajetórias e atores.

Segundo Michel Godet (1987), cenário é “o conjunto formado pela descrição coerente de uma situação futura e pelo encaminhamento dos acontecimentos permitem passar da situação origem à situação futura”. Os cenários podem ser caracterizados em:

- cenários possíveis;

- cenários realizáveis e

- cenários desejáveis

Para Schwartz (1996), “os cenários são uma ferramenta para nos ajudar a ter uma visão de longo prazo em um mundo de grandes incertezas” isto é “para ordenar a percepção dos ambientes alternativos futuros, nos quais as decisões pessoais podem ser tomadas. Ou um conjunto de métodos organizados para sonharmos o futuro de maneira eficiente”. 
Desta forma podemos inferir que os cenários têm como foco assuntos e informações de grande importância para os tomadores de decisão, assim como os elementos imprevisíveis do ambiente que afetam o sistema em que a empresa está inserida. Propiciam um ambiente que enriquece o debate sobre questões críticas relacionadas com o futuro da organização e permitem que os dirigentes da empresa tomem decisões de risco com mais transparência.

Permitem ainda a identificação de oportunidades e de ameaças ao negócio, promovem o desenvolvimento e a análise de novas opções de futuro frente a mudanças no ambiente externo, e propiciam uma visão de futuro que pode ser compartilhada pelos membros da organização.

A aplicação do termo e seu significado propositivo dependem do contexto onde é utilizado; neste caso fala-se de cenários prospectivos, ou seja, a análise daqueles elementos que poderão influenciar no resultado dos trabalhos, no desempenho da empresa ou na execução do projeto.

Para SCHWARTZ (2000, p. 18), a análise de cenários é uma ferramenta para nos ajudar a adotar uma visão a longo prazo (com arte e criatividade), combinado com a prática da conversação estratégica, num mundo de grande incerteza política, social, econômica e tecnológica.

O estudo de cenário ganhou força após a segunda guerra mundial, com a chamada "Guerra Fria", quando surgiu a necessidade de reconstrução de partes significativas da Europa e do Japão, onde a definição de uma estratégia de trabalho implicava em conhecer de forma detalhada os cenários destruídos e os riscos envolvidos nessa reconstrução, face à possibilidade de desmoronamentos, existência de resíduos tóxicos e radioativos, material explosivo não detonado, existência de campos minados, de locomoção precária ou inexistentes, sejam aéreas, terrestres ou marítimas.

Nos anos 60 Herman Kahn, começa a promover estudos visando analisar as estratégias que poderiam ser desenvolvidas pelos inimigos e os meios que seriam necessários para a defesa e neutralização destas eventuais ações aprimorando o estudo dos cenários para serem utilizados também em nível organizacional em diferentes áreas. Por meio do Instituto Hudson, Khan divulgou um trabalho que passou a ser referência no campo prospectivo, destacando os fatores essenciais para a sobrevivência das empresas e empreendimentos em ambientes turbulentos. Os assuntos abordados no citado trabalho foram:

- Desenvolvimento de novas tecnologias;

- Mudanças e diferenças em valores sociais que afetam a produtividade;

- Detecção e exploração de novas fontes de matérias-primas; 
- Planos concretos de desenvolvimento para determinadas áreas;

- Análise e considerações políticas sobre segurança de investimentos e estabilidade das atitudes dos operários, concernente à disciplina e trabalho esforçado.

A prospecção de cenários transformou-se e atingiu novas dimensões no início dos anos 1970, com o trabalho do cenarista francês Pierre Wack, na área de planejamento do futuro da Royal Dutch Shell, salientando a necessidade de criar uma nova ferramenta que auxiliasse no planejamento de longo prazo. Tudo começou com o preço do petróleo, estável desde a II Guerra Mundial, e era considerado uma commodity estratégica, cujos custos os países consumidores tentavam manter em níveis aceitáveis.

Mas, no início da década de 70, começaram a surgir alguns indícios de mudanças. Os planejadores da Shell, entre eles Pierre Wack e Kees van der Heijden, perceberam isso e se dedicaram à pesquisa dos eventuais fatores determinantes e seu possível impacto sobre o futuro da empresa, lançando um conceito que viria a se tornar fundamental no mundo dos negócios: o de planejar, por meio de cenários, metodologia que ficou conhecida como “Planejamento de Cenários”.

Pierre Wack e seu grupo da Shell tinham o planejamento de cenários como meta principal à liberação do insight das pessoas. A finalidade dos cenários exploratórios era, segundo Heijden (2000 p.64), “ampliar a compreensão do sistema, identificar os elementos predeterminados e descobrir as conexões entre as várias forças e eventos que conduziam esse sistema, o que levaria a uma melhor tomada de decisão”.

Os resultados obtidos pela Royal Dutch Shell com o novo enfoque de ver o futuro tornaram a empresa mundialmente conhecida pelo pioneirismo na utilização de cenários, o que resultou na valorização e no reconhecimento da técnica. A partir dessa época, surgiram vários estudos baseados nos cenários. Segundo Mintzberg et alli (2000), em 1985, Porter com a sua obra Estratégia Competitiva analisou os cenários sob a perspectiva econômica, adaptando-os a uma realidade mais negocial e levando em consideração os movimentos dos concorrentes. Porter (1992) descreve a técnica de cenários como uma ferramenta no arsenal do estrategista, baseado na suposição de que, se não se pode prever o futuro especulando sobre uma variedade de futuros pode-se abrir a mente e, com sorte, chegar ao futuro correto.

Em 1988, com o surgimento da Global Business Network (GBN) - empresa de prospectiva criada por Peter Schwartz e Pierre Wack -, teve início a popularização do emprego dos cenários como instrumento de gestão estratégica para as empresas anglosaxônicas e sua divulgação e expansão em todo o mundo organizacional a partir da década de 90. 


\subsubsection{Cenários Prospectivos: Características, Enfoques e Tipologia.}

Para examinar o planejamento por cenário e o contexto no qual ele ocorre é necessário identificar e examinar suas características, enfoques e tipologias e como as mesmas afetam e são afetadas pela sua interação neste contexto. Peter Schwartz (2000) salienta que os cenários lidam com dois mundos: o mundo dos fatos e o mundo das percepções. Exploram os fatos, mas são dirigidos às percepções no interior da cabeça dos tomadores de decisão. Seu propósito é reunir e transformar informação de significância estratégica em novas percepções. Quando esse processo funciona, é uma experiência criativa que gera um insight sincero dos gestores e leva a novas idéias estratégicas além do alcance anterior da mente.

No que diz respeito ao conteúdo de um cenário, primeiramente deve-se considerar o sistema em que a organização atua. Esse sistema é composto pelo objetivo de cenarização, seu horizonte temporal e lugar. Sistema é visto como uma totalidade organizada em elementos e fenômenos interligados e interdependentes, que podem formar sistemas menores ou subsistemas daquele que está sendo considerado. O objetivo de cenarização é a questão a ser estudada nos diversos cenários propostos. O horizonte temporal é o período coberto pelo estudo de cenarização, este tempo está relacionado com objetivo principal dos cenários. Não se recomenda cenários que tenham horizonte temporal inferior a 5 anos. Finalmente o lugar é a região onde será proposta a aplicação de cenários.

Segundo Marcial \& Grumbach (2006) a arte de prospectar um cenário completo geralmente contém sete características ou componentes principais:

1. TÍTULO;

2. FILOSOFIA;

3. ATORES;

4. VARIÁVEIS;

Um cenário completo, em geral, contém 7 componentes principais: um título, uma filosofia, variáveis, atores, cenas e trajetória.

Segundo Schwartz(1996)

Título é possuidor de uma carga tremenda, pois age como sua referencia. Deve dar a idéia da lógica dos cenários e de fácil memorização.

Filosofia sintetiza o movimento ou a direção fundamental do sistema considerado para o cenário proposto.

Atores são indivíduos, grupos, decisores, organizações ou associações de classe que influenciam ou recebem influencia significativa do sistema e/ou contexto considerado no 
cenário. Segundo Godet (1993), o ator desempenha papel importante no sistema, influenciando o comportamento das variáveis, com o objetivo de viabilizar seus projetos.

Variáveis representam aspectos ou elementos relevantes do sistema ou do contexto considerado, tendo em vista o objetivo do cenário. As variáveis podem ser constantes, previsíveis e incertas.

Trajetória é o percurso ou caminho seguido pelo sistema no horizonte de tempo considerado.

Cena é uma visão da situação considerada em determinado instante do tempo, a qual descreve como estão organizados ou vinculados entre si os atores e as variáveis.

Cenários finais é a conclusão do trabalho, vinculando o conjunto da obra à quantidade de cenários vislumbrados ou pretendidos.

Importantes características não podem ser esquecidas, tais como:

$\checkmark$ A visão plural do futuro, considerada a mais importante;

$\checkmark$ Ênfase do aspecto qualitativo. Como muitas das vezes, o horizonte temporal é dilatado, as variáveis quantitativas perdem significado, em função da incerteza implícita, e os cenários baseam-se em variáveis qualitativas.

$\checkmark$ Consistência, ou seja, a compatibilidade mutua entre a filosofia, a trajetória e as cenas que o integram.

$\checkmark$ Do ponto de vista da aplicação, Stollenwerk (1988), classificam os cenários como:

1. Globais - são definidos para definir estratégias globais e englobam em sue conteúdo questões políticas, macroeconomicas, tecnológicas e sociais.

2. Focalizados - são definidos para definir estratégias regionais ou setoriais, sendo considerado os movimentos da concorrência, o mercado, riscos e investimentos, e

3. Projetos - são desenvolvidos para tomadas de decisões referentes a investimentos que envolvam grandes incertezas ou que exijam grande prazo de maturação.

Quanto à tipologia os cenários são qualificados por sua natureza ou probabilidade e podem ser classificados em normativos ou exploratórios. Os cenários normativos são aqueles que configuram futuros desejados. A lógica é: primeiro definir o futuro desejado e depois traçar as trajetórias para alcançá-lo. Os cenários exploratórios caracterizam-se por futuros 
possíveis ou prováveis do sistema, mediante a simulação e o desenvolvimento de certas condições iniciais.

Apesar de o futuro apresentar um número infinito de possibilidades e de acontecimentos, torna-se improdutivo tentar explorar todas essas possibilidades. Portanto deve-se trabalhar com o número de cenários de acordo com o perfil da empresa e os objetivos a serem alcançados. Alguns autores posicionam que mais de quatro cenários dificulta o desdobramento e entendimento dos dirigentes da empresa. Por outro lado, três cenários podem levar ao erro de considerar o intermediário como provável e tornar-se uma projeção.

Além de levar em conta as características acima observadas, Ribeiro (2001), aconselha a utilização do planejamento por cenários para:

$\checkmark$ Identificar possíveis oportunidades de negócios;

$\checkmark$ Testar a estratégia em múltiplos cenários;

$\checkmark$ Monitoramento da execução da estratégia;

$\checkmark$ Pesquisar mudanças no ambiente para determinar quais estratégias deverão ser adaptadas ou alteradas para a sobrevivência dos negócios;

$\checkmark$ Reduzir as incertezas em relação à capacidade da liderança de promover ajustes;

$\checkmark$ Incrementar a qualidade do pensamento estratégico (reduzir pensamentos rotineiros)

É importante salientar da importância de se respeitar, no processo de construção de cenários prospectivos, os seus passos fundamentais (preparação, características, enfoques, tipologias e mudança do modelo mental gerencial), que permitem muito mais do que projetar cenários satisfatórios, como também conduz a uma transformação quase que revolucionária na empresa, tão importante quanto o desenvolvimento dos próprios cenários.

Enfim, planejar cenários é determinar os objetivos e os meios eficazes para alcançá-los, preparando a organização ao futuro incerto e descontínuo. Nesse contexto, a atividade contínua de análise do futuro torna-se quase uma exigência lógica e operacional para as organizações sobreviverem ao desafio da mudança e desafios do mundo globalizado.

\subsubsection{Técnicas e Métodos de elaboração de análise de cenários prospectivos}

Várias são as técnicas de apoio e métodos que auxiliam na construção de cenários prospectivos. No entanto, independentemente da técnica utilizada, "somente a análise de 
múltiplos cenários é a ferramenta indicada para examinar incertezas e expandir o pensamento das pessoas” (SCHOEMAKER apud MARCIAL \& GRUMBACH, 2006).

Para Godet e Roubelat apud Marcial \& Grumbach (2006), não há apenas um método de construção de cenário, mas vários deles. Os autores salientam que para construir cenários e definir estratégias, é necessário usar ferramentas simples, a fim de que os resultados possam ser assimilados pelos usuários.

Marcial \& Grumbach (2006) dividem as técnicas de prospecção de cenários em três grupos:

1. De ajuda à criatividade: Brainstorming, Sinética, Análise Morfológica e Questionários e Entrevistas;

2. De avaliação: Método Delphi, Método dos Impactos Cruzados e Modelagem e Simulação e,

3. De análise de multicritério: Método dos Concursos, Método Pattern, Método Electre.

De uma maneira geral essas técnicas são utilizadas de modo combinado nas organizações. No ambiente moderno da prospecção, porém, as qualitativas, por exprimirem o potencial criativo das pessoas, estão mais em destaque do que as quantitativas.

Em relação às “de ajuda à criatividade”, Marcial \& Grumbach (2006) definem Brainstrorming como uma técnica de trabalho em grupo na qual a intenção é produzir o máximo de soluções possíveis para um determinado problema. A Sinéctica é uma técnica de trabalho em grupo para geração de idéias criativas acerca de determinado problema que utiliza principalmente analogias. As discussões são realizadas tomando-se por base dois conceitos: “fazer o estranho familiar” e “fazer o familiar estranho”. A Análise Morfológica consiste em explorar de forma sistemática os futuros possíveis a partir do estudo de todas as combinações resultantes da decomposição de um sistema, ou seja, a decomposição da totalidade do sistema em vários elementos e na identificação das várias formas e valores que estes podem assumir, os quais são chamados de atributos. A respeito dos Questionários e Entrevistas são instrumentos auxiliares das técnicas acima descritas que podem ser utilizados na organização, no sentido de democratizar suas idéias, opiniões e informações, aumentando a amplitude da população-alvo, na utilização das técnicas de prospecção de cenários.

O segundo grupo de técnicas de apoio à prospecção é o “de Avaliação”, cujo objetivo principal é estimar as mudanças de comportamento de determinadas variáveis e suas repercussões num dado sistema analisado. O método "Delphi" é reconhecido como um dos melhores instrumentos de previsão qualitativa. O princípio do método é intuitivo e interativo. 
Implica a constituição de um grupo de especialistas em determinada área do conhecimento, que respondem a uma série de questões. Assim sendo no método Delphi atuam dois grupos: o de peritos, que são consultados a distancia e de analistas que analise e interpreta as respostas. O método se propõe a levantar as possibilidades de ocorrência e sua pertinência em relação ao problema. O Método de Impactos Cruzados engloba uma família de técnicas que visam avaliar a influência que a ocorrência de determinado evento teria sobre as probabilidades de ocorrência de outros eventos; leva em conta a interdependência de várias questões formuladas, possibilitando que o estudo adquira um enfoque mais global, mais sistêmico e portanto, mais de acordo com a visão prospectiva e utilizado também para corrigir inconsistências.

O terceiro e último grupo de técnicas de apoio à prospecção são as "de análise de multicritério” cujo objetivo é de facilitar as decisões referentes a um determinado problema, quando se tem que levar em conta múltiplos e diversos pontos de vista. Sua aplicabilidade prioriza ou diminui os vários fatores que devem ser levados em consideração. O Método dos Concursos - é um método de seleção nos quais os vários aspectos do problema, ou critérios são considerados do mesmo modo que as diversas provas de um concurso. Agrupam-se os dados dentro de cada critério, em seguida pondera-se sua importância de acordo com o peso atribuído a cada critério. O Método Pattern - Trata-se de relacionar os diferentes níveis hierarquizados de um problema. Constroem-se arvores colocando-se no topo os objetivos a serem alcançados e, nos níveis intermediários, as metas e submetas necessárias para se alcançar os objetivos. Cada aresta da arvore recebe um peso de acordo com sua importância para atingir-se os objetivos iniciais. O Método Electre - trata-se da modelagem de preferências baseada na comparação de algumas ações segundo critérios preestabelecidos.

Estes métodos, de acordo com Marcial \& Grumbach (2006), são efetuados dentro da de prospecção em duas etapas:

1. Na primeira etapa, classificam-se os diversos aspectos que vão compor as variáveis do cenário em estudo;

2. Na segunda, agregam-se as classificações obtidas, ou por ponderações - caso da aplicação dos Métodos dos Concursos, de Pattern e do CPE, ou por uma regra que permita comparar os diversos aspectos, considerando certos níveis de concordância e discordância - caso da aplicação do Método Electre e seus derivados. 


\section{MÉTODOS PARA A CONSTRUÇÃO DE CENÁRIOS PROSPECTIVOS}

Para fins de investigação e estudo este trabalho aborda os métodos de elaboração de cenários que possuem base conceitual, passos definidos e filosofia:

- $\quad$ Método descrito por Michel Godet;

- $\quad$ Método descrito por Peter Schwartz;

- $\quad$ Método descrito por Michael Porter;

- $\quad$ Método descrito por Grumbach.

\subsection{Método descrito por Michel Godet}

A abordagem para cenários prospectivos proposta por Michel Godet tem um foco bem definido: ambiente de negócios.

O método de elaboração de cenários exploratórios descritos por Godet no "Manual da prospectiva estratégica: da antecipação a ação” compoem-se de 6 etapas conforme demonstrado na figura 4 abaixo:

\section{Figura 4 - Fases do Método Descrito por Godet}

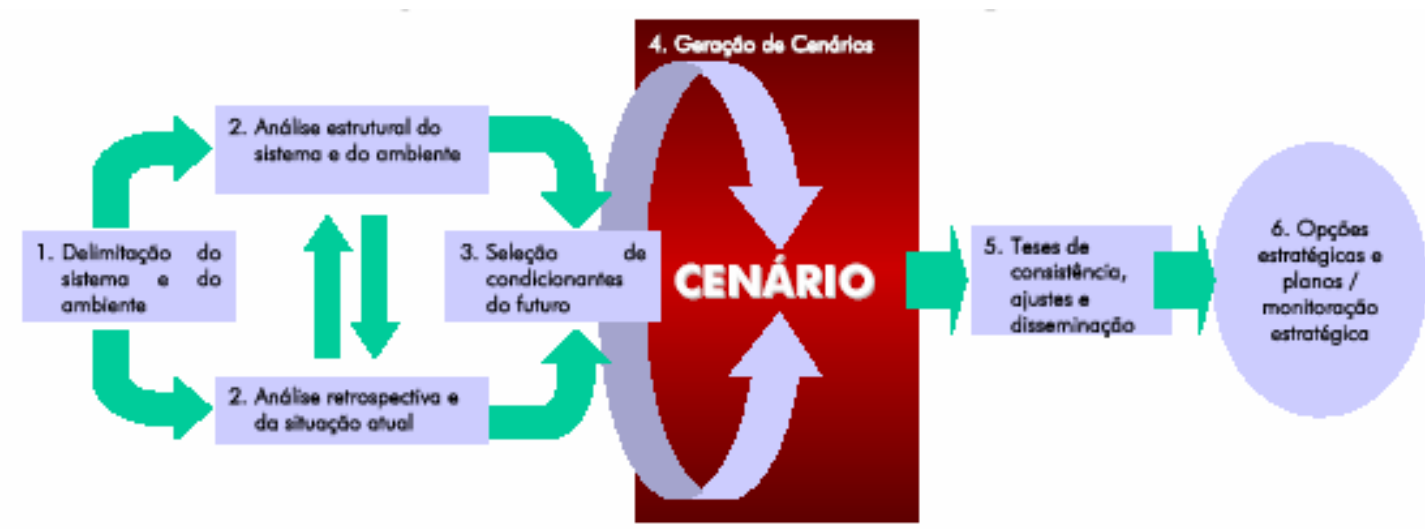

Fonte: Marcial \& Grumbach (2002, p.71).

O quadro 2 elucida o entendimento destas etapas que se inicia com a construção de uma Base Analítica e Histórica com a delimitação do fenômeno a ser estudado (variáveis internas); análise do ambiente externo (variáveis externas); delimitação do sistema e identificação das variáveis chaves; em seguida são realizados dois estudos analíticos: 1) o retrospectivo que visa identificar os mecanismos de inércia e de mudança, tendências emergentes e os atores motores do sistema e ambiente considerados; e 2) o da situação atual visando identificar os "germes de mudança” e os projetos atuais dos atores externos e internos relevantes. 
Na segunda etapa com a Elaboração dos Cenários e de Previsões Quantitativas, é realizado o mapeamento das estratégias dos atores relevantes utilizando-se um método estruturado. O passo seguinte é o estabelecimento de hipóteses probabilizadas sobre tendências, mudanças e outras questões chaves para o futuro do sistema e ambientes considerados através de consultas a especialistas e de análise de impacto cruzados e identificação das combinações mais relevantes, finalizando-se com a quantificação dos cenários, utilizando estes como insumos para o uso de modelos de simulação e quantificação.

Na terceira e última fase com a Formulação de Estratégias e Planos de Ação consiste no desenvolvimento de recomendações quanto às estratégias alternativas face aos cenários e de sua operacionalização em planos táticos ou de ação.

\section{Quadro 2 - Etapas do Método Michel Godet}

\begin{tabular}{|c|c|c|}
\hline Etapa & Fase & Objetivo \\
\hline \multirow{3}{*}{ 苞 } & $\begin{array}{l}\text { 1. Delimitação do sistema e do } \\
\text { ambiente }\end{array}$ & $\begin{array}{l}\text { Especificar a abrangência do estudo e } \\
\text { definir o sistema. }\end{array}$ \\
\hline & $\begin{array}{l}\text { 2. Análise estrutural do sistema e } \\
\text { do ambiente }\end{array}$ & $\begin{array}{l}\text { Elaboração de uma lista preliminar das } \\
\text { variáveis relevantes do sistema e de seus } \\
\text { principais atores. }\end{array}$ \\
\hline & $\begin{array}{l}\text { 3. Seleção das condicionantes do } \\
\text { futuro }\end{array}$ & $\begin{array}{l}\text { Identificar as tendências de peso, os fatos } \\
\text { portadores de futuro, os fatores } \\
\text { predeterminados, as variantes e as } \\
\text { alianças existentes entre os atores. }\end{array}$ \\
\hline \multirow{2}{*}{ 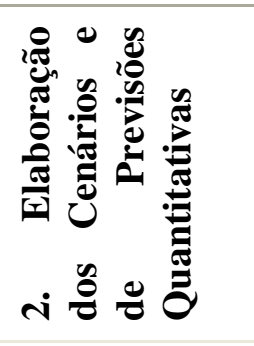 } & $\begin{array}{l}\text { 4. Geração de cenários } \\
\text { alternativos }\end{array}$ & $\begin{array}{l}\text { Decompor cada variável explicativa em } \\
\text { seus possíveis comportamentos ou } \\
\text { estados futuros, segundo as estratégias } \\
\text { dos atores. }\end{array}$ \\
\hline & $\begin{array}{l}\text { 5. Testes de consistência, ajustes } \\
\text { e disseminação. }\end{array}$ & $\begin{array}{l}\text { Assegurar a coerência dos } \\
\text { encaminhamentos } \\
\text { imagens }\end{array}$ \\
\hline ल & $\begin{array}{l}\text { 6. Opções estratégicas e planos } \\
\text { de monitoração estratégica. }\end{array}$ & $\begin{array}{l}\text { Elaboração das opções e planos } \\
\text { estratégicos a partir da revisão dos } \\
\text { cenários propostos. }\end{array}$ \\
\hline
\end{tabular}




\subsection{Método Descrito por Peter Schwartz ou da Global Busines Network (GBN)}

Nesse método são levados em consideração, em todas as etapas os "modelos mentais" dos dirigentes - visão de mundo, preocupações e incertezas conforme esquema apresentado na figura 5 abaixo:

\section{Figura 05 - Fases do Método Descrito por Peter Schwartz}

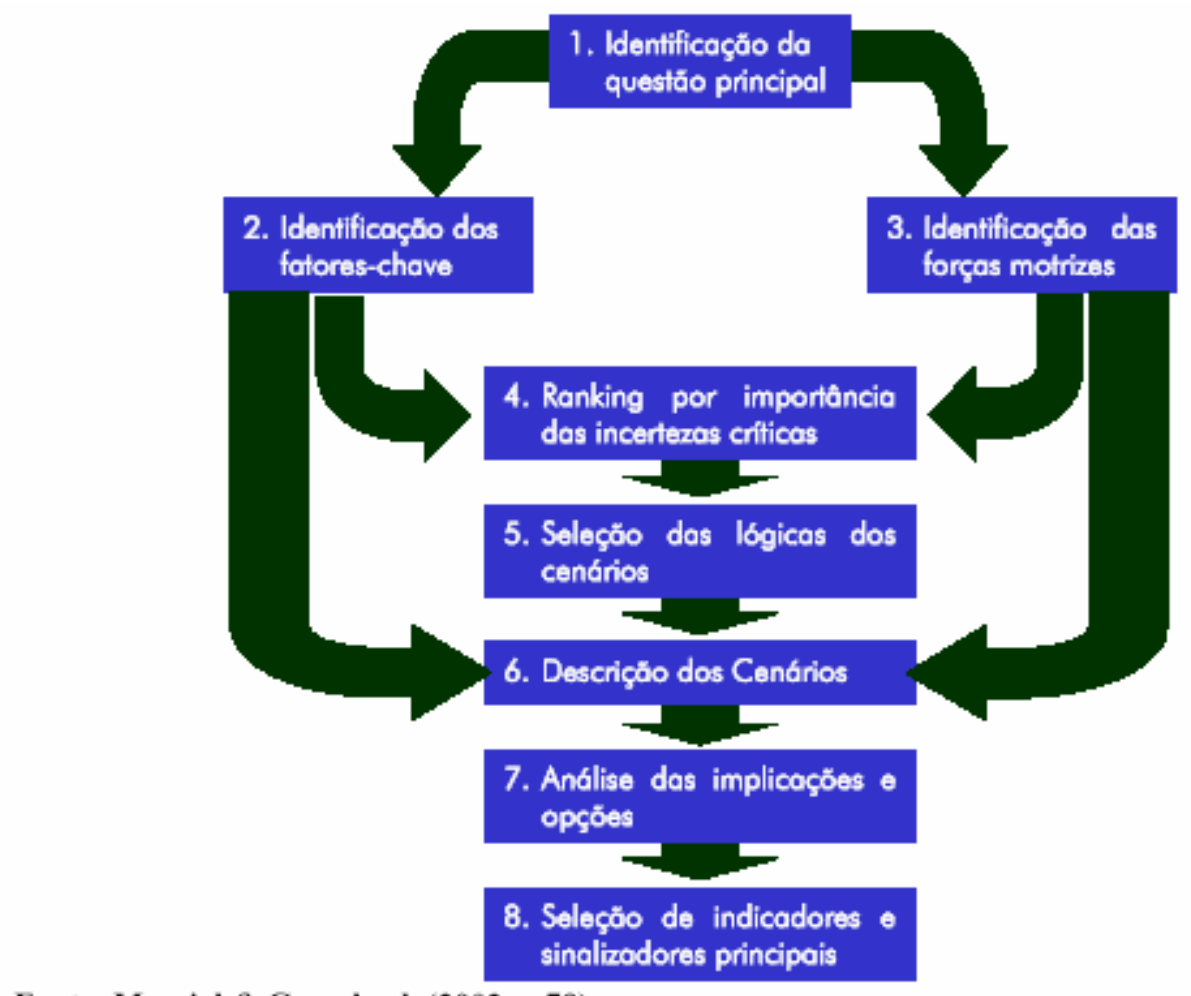

Fonte: Marcial \& Grumbach (2002, p.78).

Schwartz (2000) sugere que, antes de iniciar o processo de construção de cenários, devem-se examinar os "modelos mentais" usados na avaliação do futuro. Somente após este mapeamento é que se deve partir para a análise dos modelos dos dirigentes.

Conforme detalhado no quadro 3, a metodologia de Schwartz para a elaboração de cenários prospectivos compõe-se de três etapas subdividido em oito fases.

A primeira etapa responsável pela Análise do Micro-ambiente inicia-se a identificação das questões ou decisões estratégicas que motivou a construção dos cenários alternativos. Em seguida realiza-se a identificação das principais forças do ambiente (fatores-chave) que se referem ao comportamento da demanda e dos clientes, concorrentes, regulação governamental, fornecimento de insumo, etc. 
Com base nos elementos anteriores, parte-se para Análise do Macro-ambiente com a pesquisa das forças (tendências) motrizes que podem influenciar os fatores-chave identificados na etapa anterior. São forças menos óbvias de se identificar, mas que podem influenciar ou impactar fortemente a evolução da questão principal e os fatores-chave definidos. Essas forças são os elementos que movem o enredo de um cenário. Nesta fase devem-se diferenciar aquelas forças motrizes que são predeterminadas de outras altamente incertas, além disso, será necessário hierarquizar estas forças segundo os níveis de relevância e de incerteza.

Na quinta fase trabalha-se na escolha das "lógicas” dos cenários que são, de fato, os eixos (trajetórias) em torno dos quais os cenários vão se diferenciar. Determinar estes eixos constitui uma das atividades mais importantes do processo de construção de cenários.

Em seguida, na etapa do Desenvolvimento de Cenários, realiza-se o detalhamento dos cenários esboçados com atenção específica para os fatores e tendências de cada cenário e sua evolução configurada, ao final todos os cenários devem ser apresentados sob a forma de uma narrativa.

Nas duas fases finais, devem-se explicitar as implicações (impactos) dos cenários sobre a organização e montar um sistema de indicadores para monitoração. Finalmente, é preciso saber, o mais rápido possível, qual dos cenários está mais próximo da realidade. Para tanto, é preciso investir na concepção de indicadores que possibilitem monitorar o ambiente externo continuamente. 


\section{Quadro 3 - Etapas do Método Peter Schwartz ou da Global Busines Network (GBN)}

\begin{tabular}{|c|c|c|}
\hline Etapa & Fase & Objetivo \\
\hline \multirow{2}{*}{ 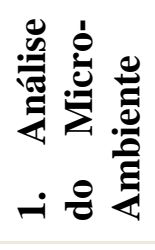 } & $\begin{array}{l}\text { 1. Identificação da questão } \\
\text { principal }\end{array}$ & $\begin{array}{l}\text { Definição da questão estratégica que motivou a } \\
\text { construção dos cenários alternativos. }\end{array}$ \\
\hline & $\begin{array}{l}\text { 2. Identificação das principais } \\
\text { forças do ambiente (fatores- } \\
\text { chave). }\end{array}$ & $\begin{array}{l}\text { Listar os fatores-chaves que incidem diretamente } \\
\text { sobre as decisões e que dizem respeito ao micro- } \\
\text { ambiente da organização. }\end{array}$ \\
\hline \multirow{3}{*}{ 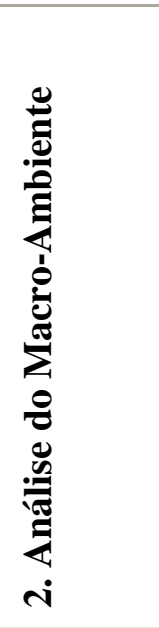 } & $\begin{array}{l}\text { 3. Identificação das forças } \\
\text { motrizes. }\end{array}$ & $\begin{array}{l}\text { Identificar as forças e tendências econômicas, } \\
\text { sociais, políticas, ambientais e tecnológicas que } \\
\text { tem pertinência evidente com as questões } \\
\text { estratégicas. }\end{array}$ \\
\hline & $\begin{array}{l}\text { 4. Mapeamento dos elementos } \\
\text { pré-determinados e das } \\
\text { incertezas críticas }\end{array}$ & $\begin{array}{l}\text { Hierarquização por importância e incerteza: } \\
\text { identificadas e exploradas as forças motrizes, é } \\
\text { preciso separar os elementos predeterminados } \\
\text { das incertezas críticas. }\end{array}$ \\
\hline & $\begin{array}{l}\text { 5. Seleção das lógicas dos } \\
\text { cenários. }\end{array}$ & $\begin{array}{l}\text { Análise do comportamento das variáveis } \\
\text { classificadas como incertezas críticas, que devem } \\
\text { ser posicionadas nos eixos ao longo dos quais os } \\
\text { cenários serão descritos. }\end{array}$ \\
\hline \multirow{3}{*}{ 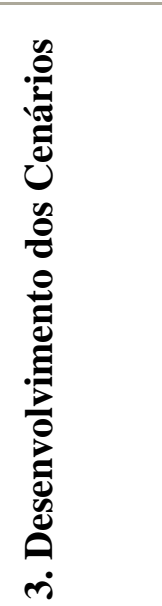 } & 6. Descrição dos cenários & $\begin{array}{l}\text { Apresentação dos cenários em forma narrativa, } \\
\text { explicando-se detalhadamente. }\end{array}$ \\
\hline & $\begin{array}{l}\text { 7. Análise das implicações e } \\
\text { opções. }\end{array}$ & $\begin{array}{l}\text { Verificar em cada um dos cenários as } \\
\text { implicações das decisões, as vulnerabilidades da } \\
\text { organização e as oportunidades existentes. }\end{array}$ \\
\hline & $\begin{array}{l}\text { 8. Seleção dos principais } \\
\text { indicadores e sinalizadores }\end{array}$ & $\begin{array}{l}\text { Definir indicadores que possibilite um } \\
\text { monitoramento prospectivo }\end{array}$ \\
\hline
\end{tabular}




\subsection{Método de Cenários Industriais de Michael Porter}

O método descrito por Porter (1996) tem como foco a indústria e como objetivo a elaboração de cenários industriais. Parte do pressuposto de que os cenários prospectivos são a melhor ferramenta a ser utilizada por uma empresa no momento de escolher sua estratégia competitiva em um ambiente de grandes incertezas com relação ao futuro, composta de 8 fases conforme esquematizado na figura 6 abaixo:

\section{Figura 06 - Fases do Método descrito por Michel Porter}

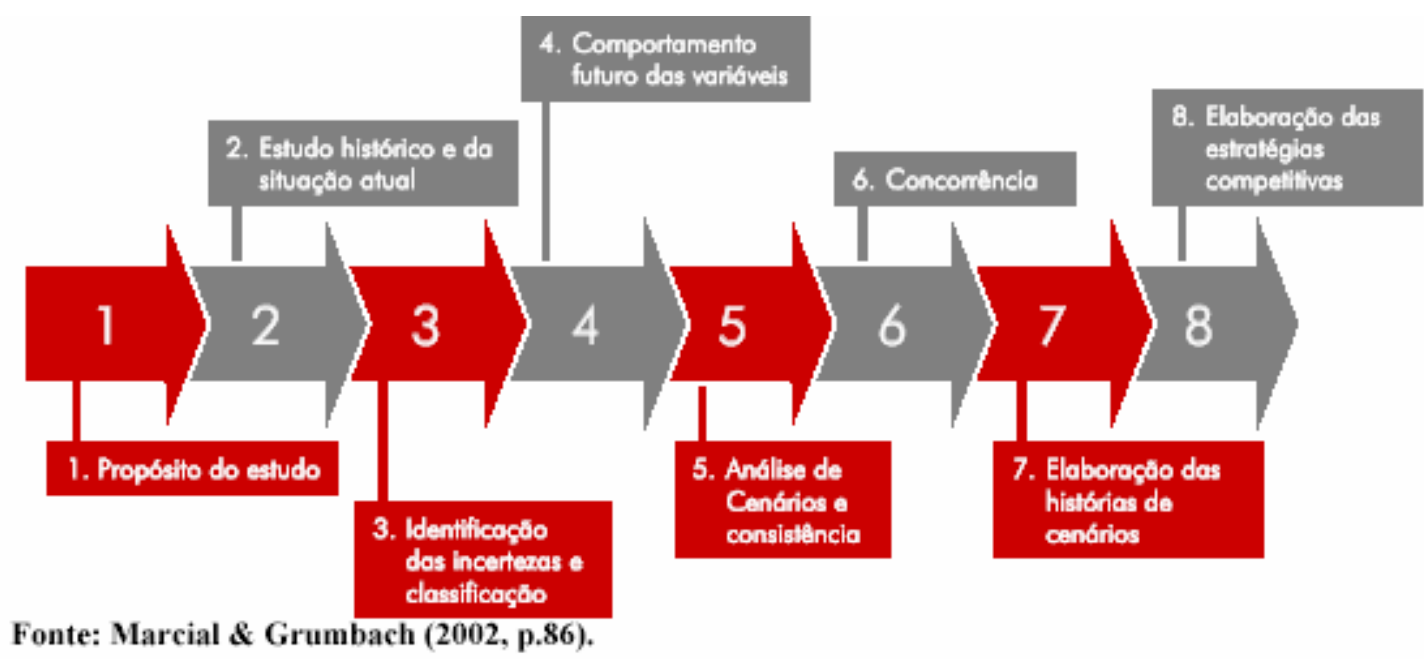

Baseia-se também no fato de que os possíveis comportamentos de qualquer empresa são funções do comportamento do macroambiente interagindo como o ramo industrial da empresa e que, por isso, ambos devem ser estudados.

O autor afirma que as incertezas relacionadas a qualquer uma das cinco forças competitivas, as quais constituem a base conceitual para a construção de cenários industriais, devem ser consideradas na construção de cenários.

Define a entrada de novos concorrentes, a ameaça de substitutos, o poder de negociação dos compradores, o poder de negociação dos fornecedores e a rivalidade entre os concorrentes como sendo as cinco forças competitivas, as quais englobam as regras da concorrência. Estas forças são a base da definição das estratégias competitivas da empresa.

A metodologia prevê que os estudos das variáveis macroambientais mercadológicas serão analisadas de forma harmônica e interativa, explicitando o comportamento da 
concorrência. O produto final servirá como subsídio para a tomada de decisão na empresa, principalmente, no que diz respeito à definição de suas estratégias competitivas.

Conforme quadro3 o processo inicia-se com a fixação dos Propósitos do Estudo prospectivo, sua amplitude e ambiente temporal. Na segunda fase realiza-se o Estudo Histórico e da Situação Atual da estrutura da indústria e sua análise para que se possa desenvolver uma compreensão do comportamento passado e atual da indústria, além de facilitar a identificação de todas as incertezas que podem afetá-la.

Na terceira faz ocorre a Identificação e Classificação das Incertezas que envolvem a indústria e sua estrutura. $\mathrm{O}$ autor considera que pode ser difícil reconhecer fontes de incerteza e sugere uma série de passos os quais se iniciam com a elaboração de uma lista de variáveis que impactarão consideravelmente a indústria nos próximos anos e a identificação do grau de incerteza de cada variável. Esta lista deverá sofrer uma depuração por meio da classificação das variáveis identificadas em variáveis constantes, predeterminadas e incertas. As variáveis constantes e as predeterminadas, são separadas da lista, pois não determinam cenários. O mesmo autor define variáveis constantes como sendo aquelas formadas por aspectos da estrutura com pouca probabilidade de sofrerem mudanças e as variáveis predeterminadas como sendo áreas cuja estrutura irá se modificar; sendo a mudança, em grande parte, previsível. Estas variáveis serão recuperadas no momento da descrição dos cenários, visto que são elementos importantes da estrutura da empresa e não poderão ficar de fora da descrição dos cenários.

Para a determinação dos cenários, utilizam-se somente as variáveis incertas, ou seja, as variáveis que constituem os aspectos da estrutura futura que dependem de incertezas não solucionáveis, as quais determinam os cenários.

A quarta etapa consiste no estudo do Comportamento Futuro das Variáveis. Para a checagem das variáveis consideradas incertas poderá ser utilizada a consulta a peritos. Durante a consulta será verificado se existe mais alguma variável a ser acrescentada, como também verifica-se quais as causas dessas incertezas e os possíveis desdobramentos para estas variáveis. Poderão ser questionadas quais ações de curto e de longo prazo que deverão ser desencadeadas para viabilizar esses acontecimentos futuros. 
A lista final das variáveis incertas, elaborada após a última checagem, deverá ser classificada em variáveis dependentes e independentes, de acordo com a identificação dos fatores causais dos elementos incertos. As incertezas independentes são os elementos da estrutura da indústria cuja incerteza independe de outros elementos da estrutura. As fontes de incerteza podem estar dentro da indústria (por exemplo, comportamento dos concorrentes) ou fora dela (por exemplo, o preço de energia). As incertezas dependentes são os elementos da estrutura, que serão em grande parte ou inteiramente determinados pelas incertezas independentes, ou seja, as que são função de outros elementos da indústria.

Apenas as independentes constituem uma base adequada para a construção de cenários, pois são fontes reais de incertezas. As dependentes são resolvidas, uma vez feitas suposições sobre as independentes, tornando-se assim parte de cada cenário.

A todo o momento é importante verificar se as classificações feitas anteriormente permanecem coerentes ao longo do processo. Neste momento, será trabalhada a lista de variáveis incertas independentes, com classificação em ordem de importância e separação em dois grupos: as mais e as menos importantes. Para cada variável importante deverão ser identificados os diversos comportamentos futuros possíveis, levando-se em consideração a opinião dos peritos, caso tenham sido consultados, e a opinião da gerência sênior da empresa.

Ao final dessa análise obtém-se um leque de possíveis cenários que constituam objeto para a quinta fase que representa a Análise de Cenários e Consistência. Os cenários inconsistentes são eliminados e apenas nos internamente consistentes incorpora-se o movimento da concorrência e suas implicações.

$\mathrm{Na}$ sexta fase, identifica-se a Concorrência e quais serão os seus possíveis comportamentos em cada cenário determinado. Para tanto, faz-se necessário o conhecimento das estratégias dos concorrentes para a identificação de seus possíveis comportamentos futuros. É importante destacar que o comportamento dos concorrentes pode afetar a velocidade e a direção das mudanças estruturais do cenário.

A sétima etapa consiste na Elaboração de Cenários e das estórias de cada cenário. Elas deverão conter a descrição minuciosa do comportamento das variáveis incertas independentes e dependentes, das mudanças estruturais predeterminadas e dos elementos constantes da 
estrutura da indústria. Serão, também, descritas as interligações entre essas variáveis e especificados todos os fatores causais.

Após o desenvolvimento dos diversos cenários, realiza-se a ultima fase que trata da elaboração das Estratégias Competitivas da empresa. Nesta fase, os dirigentes terão oportunidade de vislumbrar a empresa nos possíveis contextos e definir quais as manobras que ela deverá fazer para criar seu próprio futuro. 


\section{Quadro 3 - Etapas do Método Michael Porter}

\begin{tabular}{|c|c|}
\hline Fase & Objetivo \\
\hline 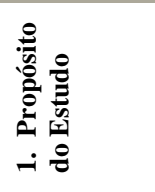 & $\begin{array}{l}\text { Fixação de propósitos de estudo, sua amplitude e ambiente temporal, estudo } \\
\text { histórico e atual da estrutura da indústria e do passado para identificar todas } \\
\text { as incertezas que podem afetá-las. }\end{array}$ \\
\hline 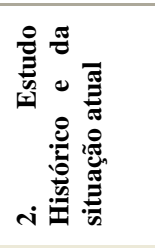 & $\begin{array}{ll}\checkmark & \text { Estudo da Estrutura; } \\
\checkmark & \text { Identificação das incertezas críticas; } \\
\checkmark & \text { Elaboração de uma lista de variáveis que poderão causar } \\
& \text { consideráveis impactos sobre a indústria; } \\
\checkmark & \text { Identificação do grau de incerteza de cada variável. }\end{array}$ \\
\hline 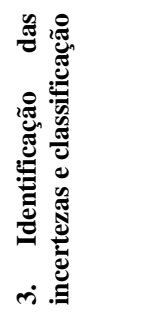 & $\begin{array}{l}\text { Separar a lista das variáveis constantes e das predeterminadas, pois as } \\
\text { variáveis constantes não determinam cenários. Para a determinação dos } \\
\text { cenários utilizam-se apenas as variáveis incertas, ou seja, as variáveis que } \\
\text { constituem aspectos da estrutura futura e que dependem de incertezas não } \\
\text { solucionáveis. }\end{array}$ \\
\hline + & $\begin{array}{l}\checkmark \text { Checagem das variáveis incertas; } \\
\checkmark \text { Verificação das causas das incertezas e possíveis desdobramentos; } \\
\text { Classificação em variáveis dependentes e independentes; }\end{array}$ \\
\hline 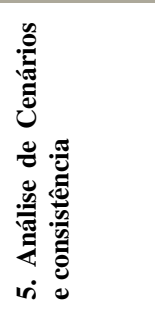 & $\begin{array}{l}\text { Analisar os possíveis Cenários e Consistência: } \\
\checkmark \text { Os considerados inconsistentes devem ser postos de lado e apenas os } \\
\text { internamente consistentes é que se habilitarão a uma análise mais } \\
\text { profunda, que leve em consideração o comportamento de cada } \\
\text { variável, chegando-a em relação às demais. }\end{array}$ \\
\hline 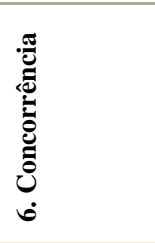 & $\begin{array}{l}\text { Identificar quem são os concorrentes e quais os seus comportamentos } \\
\text { possíveis em cada cenário, para isso, é necessário conhecer as estratégias, } \\
\text { destacando que o comportamento dos concorrentes pode afetar a velocidade } \\
\text { e o rumo das mudanças estruturais do cenário. }\end{array}$ \\
\hline 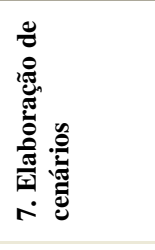 & $\begin{array}{l}\text { Elaborar as histórias de cenários: deve conter a descrição minuciosa do } \\
\text { comportamento das variáveis incertas dependentes e independentes, das } \\
\text { mudanças estruturais predeterminadas e dos elementos constantes da } \\
\text { estrutura da indústria. São também descritas as interligações dessas variáveis } \\
\text { e especificados todos os fatores causais. }\end{array}$ \\
\hline 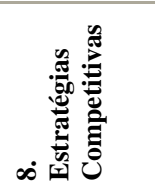 & $\begin{array}{l}\text { Elaboração das Estratégicas competitivas: os dirigentes têm a oportunidade } \\
\text { de vislumbrá-la nos contextos possíveis e de definir as manobras que ela } \\
\text { deverá executar para criar seu próprio futuro. }\end{array}$ \\
\hline
\end{tabular}




\subsection{Método prático descrito por Grumbach}

O método para elaboração de cenários prospectivos descrito por Raul Grumbach (2000) baseia-se nos conceitos definidos pela prospectiva de que existem vários futuros possíveis e de que o futuro não será, necessariamente, uma extrapolação do passado. Para atingir o objetivo final dos estudos de cenários prospectivos, ou seja, a definição das estratégias da organização, o autor propõe quatro fases distintas, conforme apresenta a figura 6 abaixo:

\section{Figura 06 - Fases do Método descrito por Raul Grumbach}

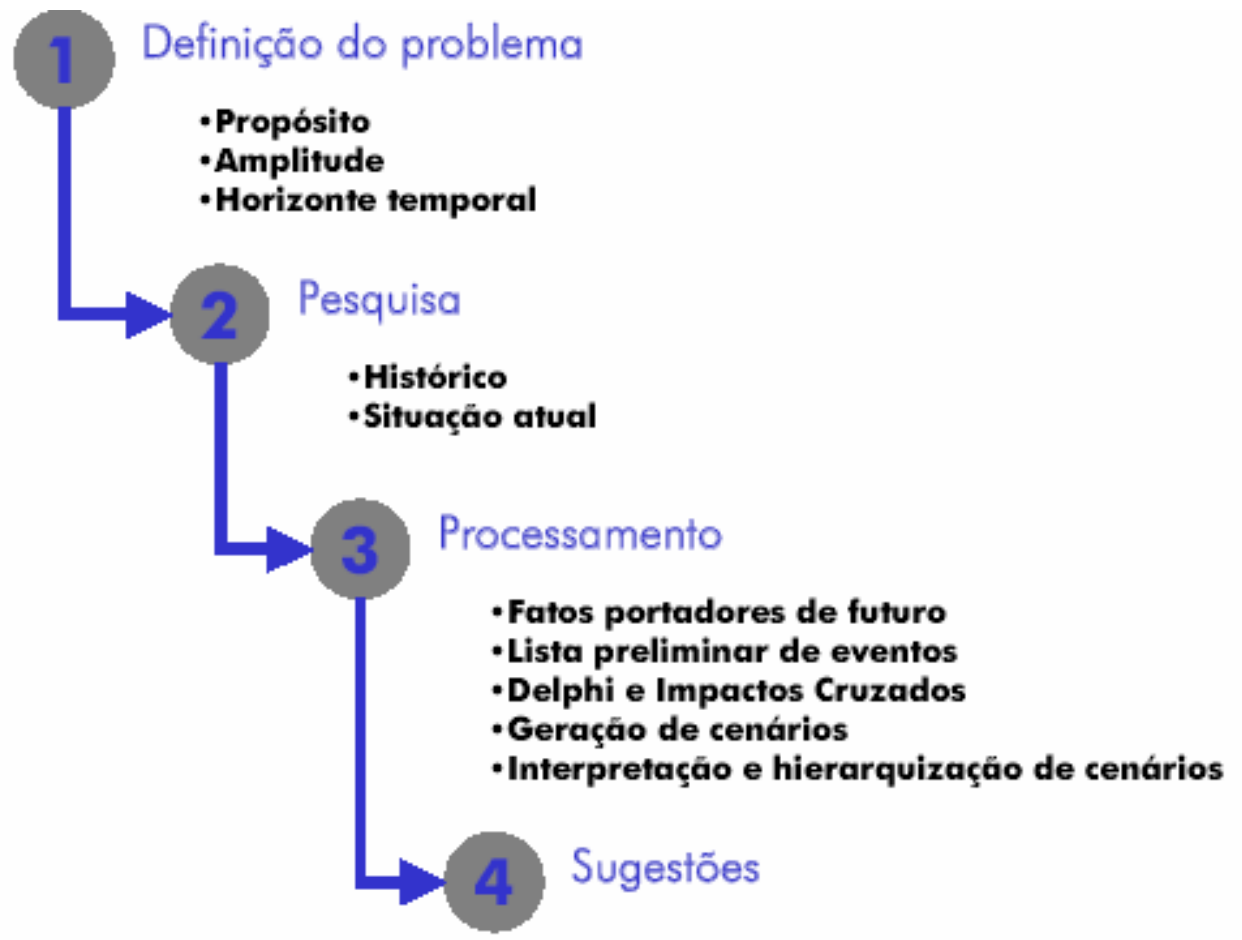

Fonte: Marcial \& Grumbach (2002, p.106).

Conforme detalhamento apresentado no quadro 4, o processo é iniciado com o Conhecimento do Problema pelo grupo de estudos de cenários. Nessa fase os propósitos do estudo e os temas a serem estudados são discutidos. Em primeiro lugar definem-se de forma clara os contornos e limites desse problema, bem como seus elementos essenciais: amplitude geográfica, nível de profundidade e horizonte temporal. Neste momento, também são definidos quem serão os peritos convidados a participar dos trabalhos. Também é importante nesta fase conhecer com detalhes o pensamento dos dirigentes da organização, como, por exemplo, seus principais juízos de valor a respeito do tema que será estudado e suas principais preocupações e expectativas. Essas informações poderão servir ao grupo como parâmetros na definição da escala de prioridades durante o decorrer dos trabalhos, na fase de análise dos 
cenários e para determinar se um assunto deverá ser analisado com maior profundidade ou não. Também serão utilizadas na fase de definição de uma hierarquização dos eventos futuros.

A segunda fase definida pelo autor como Pesquisa consiste no Diagnóstico do Problema, quando então será realizado minucioso levantamento das variáveis externas e internas do sistema em pauta; pesquisa retrospectiva; construção de uma imagem do estado atual; e entendimento das causas e origens da situação atual. A fase é finalizada com a elaboração de um documento que contenha o diagnóstico de cada tema inicialmente proposto.

Grumbach (2000) argumenta que, apesar de, sob o ponto de vista da prospectiva, os acontecimentos do passado não serem fatores determinantes do que ocorrerá no futuro, o estudo do passado se torna importante, pois permite uma melhor identificação da origem de mudança, já que os germes do futuro iniciaram sua atuação no passado. O conhecimento do comportamento das variáveis no passado ajuda a compreendê-las melhor principalmente no que diz respeito a suas interligações e influências. Também serve para retratar melhor a situação em que se encontra o sistema, permitindo uma melhor compreensão e entendimento, de forma mais clara, de suas causas e origens.

A terceira fase definida como Processamento consiste na construção ou identificação das várias alternativas de futuro. Para tanto o autor sugere três etapas: uma chamada de compreensão, de concepção e a outra de avaliação. É neste momento que os fatos portadores de futuro e os fatores e agentes exógenos são identificados.

Com base nos fatos portadores de futuro, identificam-se as rupturas de tendências tendo como resultado a concepção de eventos futuros. As técnicas de ajuda à criatividade - como o brainstorming é de extrema utilidade para auxiliar na identificação de eventos futuros responsáveis pela composição dos cenários possíveis no horizonte temporal estabelecido previamente.

Grumbach (2000) faz algumas sugestões para serem utilizadas durante a depuração da lista de eventos gerados. Ele sugere que os componentes do grupo se posicionem no final do horizonte de tempo estabelecido e procurem deixar sua imaginação livre o suficiente para produzir eventos com real possibilidade de ocorrência durante aquele período e que tenham importância para a organização. 
O autor chama a atenção para o fato de que o objetivo nesta fase é a identificação das rupturas de tendência, não se devendo ficar preso às projeções do passado. Os eventos amparados apenas na imaginação dos analistas devem ser criteriosamente discutidos, não se permitindo que o estudo passe para o campo da adivinhação. Os eventos que tenham surgido após a fase de diagnóstico devem ser considerados, mesmo que não estejam amparados em fatos concretos já listados.

Sugere também que os eventos afins devem ser agrupados para evitar um número muito grande. Por último, ele alerta que os eventos devem ser formulados de modo a não permitir interpretações gradativas, evitando as palavras "aumentar" ou "diminuir", que poderão ter significados diferentes para cada perito entrevistado. Grumbach (2000) também sugere manter um máximo de 25 eventos preliminares, já que o número de cenários gerados representará a combinação de 2n, onde "n" simboliza o número de eventos listados. Após a depuração da lista de eventos futuros é formada a lista preliminar de variáveis.

A fase composta pela avaliação e interpretação das várias alternativas de futuro existentes que facilitarão a tomada de decisão. Para auxiliar o processo de avaliação, são utilizados os métodos Delphi - quando será verificada qual a probabilidade de ocorrência de um evento segundo a visão dos peritos - e dos impactos cruzados - em que os peritos opinarão a respeito da influência que a ocorrência dos eventos trará sobre a probabilidade dos demais ocorrerem.

Antes da utilização do método dos impactos cruzados deverão ser identificados os eventos definitivos. Nesta fase, deverão ser utilizadas as técnicas de análise multicritérios, que têm como objetivo facilitar a tomada de decisão em situações que envolvem múltiplos atributos ou critérios. São também úteis na priorização de várias alternativas, levando em consideração algumas condições de restrição. Os critérios de escolha têm como base os resultados da aplicação do método Delphi e as prioridades dos tomadores de decisão. O autor sugere um número não superior a 10 eventos - o que gerará um total de 1.024 cenários futuros possíveis de ocorrer.

Para a interpretação dos cenários é necessário deixar aflorar toda a capacidade de análise do grupo. Para subsidiar a percepção do grupo, visto que este dispõe de 1.024 cenários distintos para serem escolhidos, o autor sugere trabalhar com cinco cenários alternativos: o mais provável, o ideal, o exploratório otimista, o cenário tendente e o exploratório pessimista. 
O cenário mais provável é aquele com maior probabilidade de ocorrência. O cenário ideal é aquele que contempla todas as ocorrências positivas e não contempla as ocorrências negativas, sob o ponto de vista do decisor. O cenário exploratório otimista é aquele que contempla uma série de acontecimentos considerados positivos, mas que não chega a ser tão bom quanto o ideal. O cenário tendente é aquele que corresponde à projeção dos acontecimentos passados sobre o caminho a ser percorrido pela organização, observando-se que, caso os peritos não identifiquem nenhuma ruptura de tendência, confundir-se-á com o mais provável. Por último, o cenário exploratório pessimista é aquele que contempla uma série de acontecimentos negativos e que pode ser considerado como a pior das hipóteses possíveis que venha a acontecer.

Para a descrição de cada cenário, deve-se iniciar pela descrição da situação atual e dos fatos portadores de futuro e fatores e agentes exógenos que deram origem aos eventos futuros.

Deverá ser efetuado um encadeamento lógico dos acontecimentos, com base nos estudos e pesquisas realizadas previamente, dando a forma de uma história ou caminho que se estenderá até o final do horizonte temporal estabelecido.

O processo termina com a definição das estratégias - Sugestões que a empresa deverá adotar com base nos cenários elaborados. Para auxiliar a identificação de quais são as ações no presente que mais significado trarão sobre o caminho futuro, o autor sugere a realização de simulações através da alteração do valor das probabilidades indicadas pelos peritos.

Os eventos que causarem maiores alterações quando manipulados, constituem os pontos focais do problema, dando ao decisor melhor clareza do processo e indicando onde deverá efetivamente agir. Assim, a organização poderá tomar ações no presente que lhe permitam caminhar em direção ao cenário mais favorável, ou enfrentar os percalços que surgirem em seu futuro, e que não sejam possíveis de evitar. 
Quadro 4 - Fases do Método descrito por Grumbach

\begin{tabular}{|c|c|}
\hline Fase & Objetivo \\
\hline 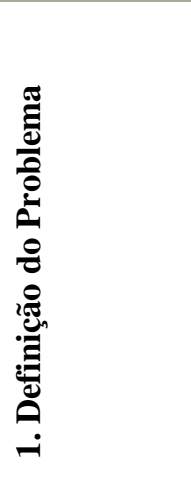 & $\begin{array}{l}\text { Discussão dos propósitos do estudo prospectivo e os temas a serem estudados: } \\
\checkmark \text { Determina a amplitude do sistema a ser analisado e estabelece o } \\
\text { horizonte temporal; } \\
\checkmark \text { Definição de quem vai compor o Grupo de Controle (analistas) e que } \\
\quad \text { peritos que serão convidados a participar do trabalho; } \\
\checkmark \text { Elaboração do cronograma de trabalho }\end{array}$ \\
\hline 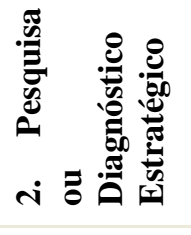 & $\begin{array}{l}\text { Levantamento minucioso das variáveis externas (oportunidades e ameaças) e } \\
\text { internas (Pontos fortes e Pontos fracos) do sistema e distribuição de tarefas. } \\
\text { Essa fase deve permitir a visão global do problema, uma das principais } \\
\text { características da prospectiva. }\end{array}$ \\
\hline 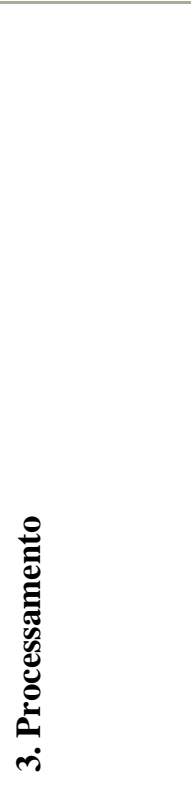 & $\begin{array}{l}\text { Esta fase engloba toda a parte analítica do método, quando os dados obtidos } \\
\text { durante a pesquisa são depurados. Nesta fase também são obtidos, através da } \\
\text { técnica de brainstorming, os eventos futuros que comporão os cenários } \\
\text { possíveis dentro do ambiente temporal. A interpretação dos cenários, que } \\
\text { possibilita o estabelecimento de uma serie de medidas preventivas deve ser } \\
\text { descrita no final desta fase. Esta fase esta subdividida em três subfases: } \\
\text { 1. Compreensão } \\
1.1 \text { - Fatos portadores de Futuro } \\
\text { 2. Concepção } \\
2.1 \text { - Lista preliminar de eventos } \\
\text { 3. Avaliação } \\
3.1 \text { - Geração de Cenários (mais provável / tendência / ideal) } \\
3.2 \text { - Interpretação e hierarquização de cenários }\end{array}$ \\
\hline 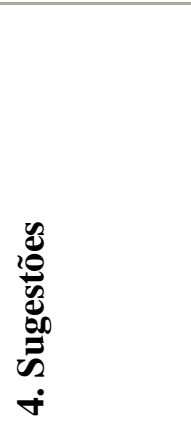 & $\begin{array}{l}\text { As sugestões a serem entregues ao decisor estratégico simbolizam o cerne de } \\
\text { todo o trabalho e sintetizam o resultado de todo encadeamento lógico de } \\
\text { idéias, que permitira a organização ou empresa executar ações no presente, } \\
\text { visando a se orientar na direção do cenário que lhe é mais favorável, ou } \\
\text { enfrentar os percalços que surgirem em seu futuro, e que não lhe foi possível } \\
\text { evitar. }\end{array}$ \\
\hline
\end{tabular}




\section{A EXPERIÊNCIA BRASILEIRA COM CENÁRIOS PROSPECTIVOS}

A elaboração de cenários é uma atividade relativamente recente no Brasil. De acordo com Buarque (2003), à exceção de algumas referências isoladas e acadêmicas, a técnica de cenários começa a ser efetivamente utilizada no Brasil na segunda metade da década de 1980 pelas empresas estatais que operam em segmentos de longo prazo de maturação, e, portanto, precisam tomar decisões de longo prazo. Um exemplo típico deste período pode ser encontrado nos estudos de cenários para projeção de demanda de energia elétrica aprofundados e ampliados pela Eletronorte, que dá início à focalização regional no Brasil. A Eletrobrás realiza, ainda hoje, estudos de mercados futuros com cenários. Já a Petrobras mantém hoje um departamento ativo de monitoramento, que gera insumos permanentes para o planejamento estratégico da empresa.

No terreno estritamente acadêmico, o Brasil apresenta as primeiras referências às técnicas de antecipação de futuro na década de 1970 e realiza, na segunda metade da década de 1980, alguma investida na produção de cenários futuros, entre os quais o trabalho de Hélio Jaguaribe (1989), intitulado Brasil 2000, que procura desenhar um cenário desejado para o Brasil com base em alguns parâmetros gerais de desenvolvimento. Trabalhos com conteúdo teórico e metodológico sobre a prospecção de futuros surgem já no fim da década de 1970, embora tenham sido muito pouco utilizados, na medida em que não existia, no mundo empresarial e governamental, uma percepção da importância da ferramenta.

Alguns trabalhos de conteúdo metodológico realizados pelo Instituto Universitário de Pesquisas do Rio de Janeiro (Iuperj) permitiu a produção de um relatório final sob a forma de manual - intitulado explicitamente de Manual de Técnicas de Previsão (Gomes de Souza, Gomes de Souza, e Abreu Silva, 1976). Esse trabalho faz uma reflexão teórica e conceitual sobre a antecipação de futuro e apresenta uma proposta metodológica e técnica para a construção de cenários. Quase na mesma época, em 1979, é publicado o livro de Henrique Rattner, Estudos do futuro - introdução à antecipação tecnológica e social, que constitui efetivamente um referencial metodológico para a prática de elaboração de cenários.

Na década de 1980, o trabalho de conteúdo diretamente econômico elaborado pelo Banco Nacional de Desenvolvimento Econômico e Social (BNDES) teve um impacto importante e iniciou uma grande discussão política sobre os cenários do Brasil. No início da redemocratização brasileira e no meio de uma incerteza em relação às alternativas de desenvolvimento futuro do país, encerrado o ciclo de crescimento e de modernização, o estudo do BNDES introduziu as alternativas de desenvolvimento brasileiro e de inserção na economia internacional. Os cenários do BNDES contribuíram para o planejamento estratégico 
do banco e levaram à introdução do cenário de integração competitiva nas formulações estratégicas do Brasil.

Em 1988, a Eletronorte realizou o primeiro grande empreendimento de construção de cenários para uma macrorregião, com um aprofundamento analítico e com a utilização de técnicas avançadas e contemporâneas de organização e sistematização de hipóteses (Eletronorte/PPM - Cláudio Porto e Consultores Associados, jun. 1988), com o objetivo de orientar, efetivamente, a empresa no seu planejamento estratégico e no seu plano de expansão.

No ano seguinte (1989), a Superintendência do Desenvolvimento da Amazônia (Sudam) aprofundou e ampliou o estudo dos cenários da Amazônia, atualizando com novos e importantes eventos que dominaram as cenas internacional e nacional, particularmente a forte emergência da questão ambiental e a pressão para preservação das florestas tropicais. Além disso, os Macrocenários da Amazônia introduziram uma importante novidade com a formulação do cenário desejado, elaborado com base em um grande esforço de consulta à sociedade organizada da região (Sudam, 1990).

Estudo realizado pelo Serviço de Apoio às Micro e Pequenas Empresas (Sebrae- PE), em 1996, traçou os cenários do ambiente de negócios das pequenas e das microempresas, procurando definir os elementos para a priorização das ações da instituição (Sebrae, 1996), e os diversos cenários elaborados pelo Serviço Nacional de Aprendizagem Industrial (Senai) com focalizações regionais e análise do impacto sobre o sistema de ensino superior e sobre a própria instituição.

Em nível regional foram realizados trabalhos pontuais no Nordeste para a definição das prioridades estratégicas de desenvolvimento regional no âmbito do Projeto Áridas (Seplan/PR, 1994). No estado do Paraná foram realizados, com o patrocínio do Paranacidade e o apoio do Ipea/Pnud, estudos de cenários com foco microrregional com o objetivo de orientar o planejamento das regiões da Associação Municipal do Oeste Paranaense (Amop) e da Associação Municipal do Setentrião Paranaense (Amusep), procurando adaptar as metodologias à sub-região de planejamento.

No final da década de 90, o governo federal, realizou um dos mais ambiciosos empreendimentos de construção de macrocenários no Brasil, o Projeto “Brasil 2020”, implementado pela Secretaria de Assuntos Estratégicos (SAE) da Presidência da República em 1998.

Buarque (2003), afirma que a utilidade desses diversos estudos para o planejamento e a efetiva tomada de decisões tem sido limitada, por um lado, em razão das descontinuidades 
de orientação das instituições patrocinadoras dos trabalhos e, por outro, em virtude da excessiva instabilidade político-institucional do Brasil. 


\section{POLÍTICAS PÚBLICAS DO TURISMO}

\subsection{O Programa de Regionalização do Turismo - Roteiros do Brasil}

O programa de Regionalização do Turismo lançado em 2004, pelo Ministério do Turismo, é considerado um modelo de gestão de política pública descentralizada, coordenada e integrada, baseada nos princípios da flexibilidade, articulação, mobilização, cooperação intersetorial e interinstitucional e na sinergia de decisões, visando atingir os seguintes objetivos:

- dar qualidade ao produto turístico;

- diversificar a oferta turística;

- estruturar os destinos turísticos;

- ampliar e qualificar o mercado de trabalho;

- aumentar a inserção competitiva do produto turístico no mercado internacional;

- ampliar o consumo do produto turístico no mercado nacional;

- aumentar a taxa de permanência e gasto médio do turista.

Para tanto a Secretaria Nacional em Políticas de Turismo do Ministério do Turismo publicou em 2004, documento que apresentou as diretrizes operacionais, composta de 9 módulos conforme figura 7, com o objetivo subsidiar o desenvolvimento turístico no Brasil. Para fins de estudo, deste trabalho, será apresentado as características do Módulo Operacional 4 que consolida os processos necessários para elaboração do Planejamento Estratégico de Desenvolvimento do Turismo Regional.

O produto resultante do planejamento estratégico no caso específico do Programa é o documento denominado Plano Estratégico de Desenvolvimento do Turismo Regional. Esse Plano estabelecerá a visão de futuro desejada pela região no que diz respeito ao turismo, composto por ações de curto, médio e longo prazo, projetos, parceiros e possíveis entidades financiadoras dos mesmos e deve ainda respeitar as diferenças e peculiaridades da região, permitindo que cada uma possa criar um modelo próprio de desenvolvimento turístico que será utilizado como principal instrumento de orientação, diálogo e negociação entre o órgão executor e os demais envolvidos. 


\section{Figura 7 - Módulos Operacionais do Programa de Regionalização do Turismo}

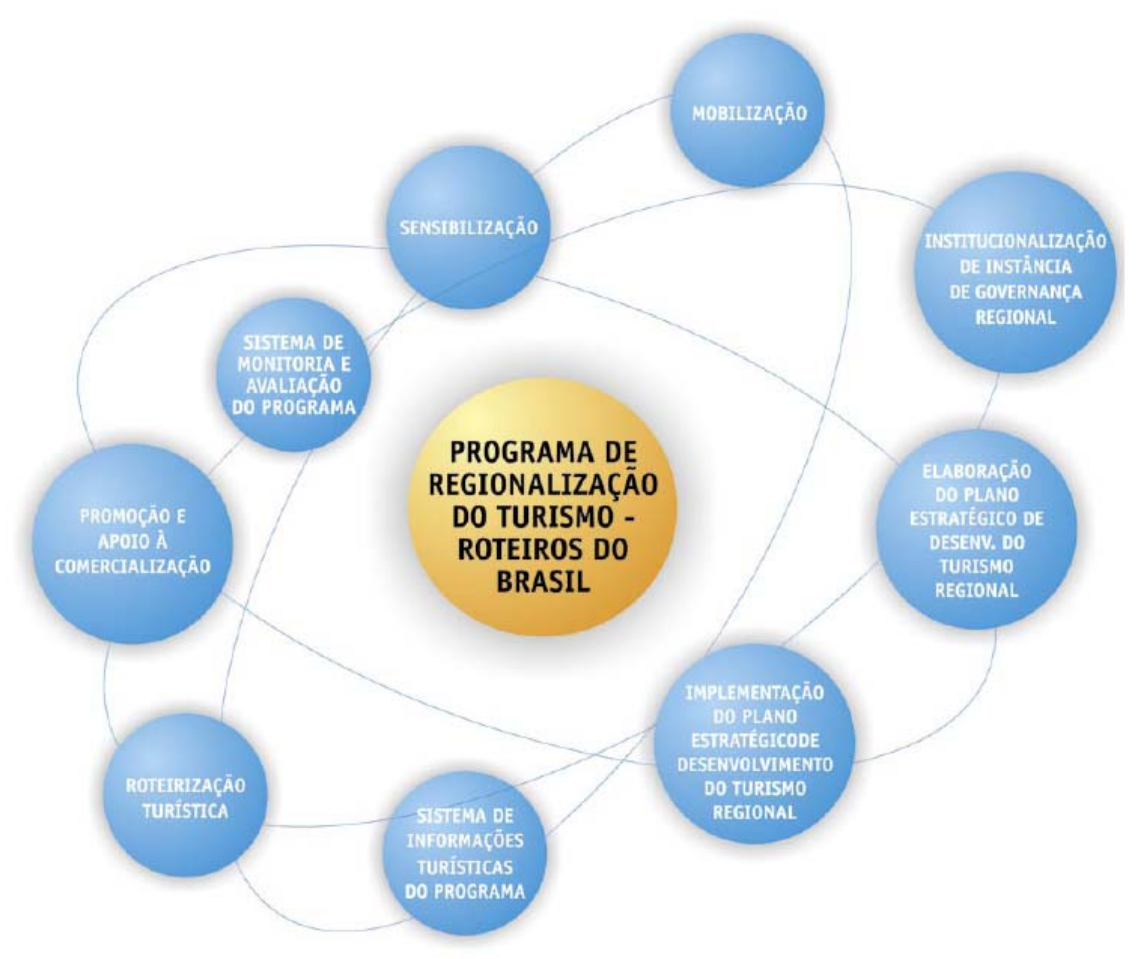

\section{Fonte: Ministério do Turismo 2004}

Neste contexto o planejamento estratégico regional deve nortear o desenvolvimento da atividade turística de forma integrada; otimizar o uso dos recursos materiais e financeiros e o emprego dos recursos humanos; evitar a duplicidade e o paralelismo de ações numa mesma região, e fornecer subsídios aos órgãos públicos para que favoreçam a integração e coordenação de ações entre si, a fim de reduzir ou eliminar entraves e barreiras na atividade turística da região, entendidas como alcançáveis por meio de estratégias direcionadas a articulação e negociação com os órgãos governamentais, não-governamentais e iniciativa privada, para que sejam somados esforços nas ações que visem ao desenvolvimento do turismo de forma regionalizada e propiciem um fluxo de comunicação eficiente.

A metodologia adotada pelo Ministério do Turismo para a elaboração de Planos Estratégicos de Desenvolvimento do Turismo Regional, é composta de duas fases principais, com suas respectivas etapas e passos a serem cumpridos.

O Plano Estratégico inclui, no mínimo, duas fases principais, com suas respectivas etapas e passos a serem cumpridos: 
Fase 1: Análise situacional da região turística e do mercado turístico a ela associado Diagnóstico.

Fase 2: Elaboração do Planejamento Estratégico.

Fase 1: Análise situacional da região turística e do mercado turístico a ela associado Diagnóstico

O instrumento empregado nessa fase é a Matriz de Sistematização de Informações, a ser disponibilizada pelo Ministério do Turismo a todas as Unidades da Federação. Essa Matriz terá a proposta de resgatar, agregar e sistematizar os dados já existentes na região em foco, como os inventários da oferta turística, as informações atualizadas da região - colhidas em outros levantamentos - assim como projetos, planos e programas anteriormente elaborados. A Matriz de Sistematização de Informações deverá ser preenchida em gabinete, contando com os atores que detêm as informações e documentos da região turística. Após esta ação, em processo participativo e com representatividade ampla dos envolvidos na elaboração do referido Plano, as informações serão atualizadas, ajustadas e validadas, para constituírem uma análise confiável da região. A partir daí, será dada continuidade ao processo de planejamento, cujo resultado será o Plano Estratégico de Desenvolvimento do Turismo Regional.

A análise situacional é dividida em seis passos:

1. Elaboração ou resgate do Inventário da oferta turística. Compreende o levantamento dos atrativos turísticos (naturais; culturais; atividades econômicas; realizações técnicas, científicas e artísticas; e eventos programados), serviços e equipamentos turísticos e infra-estrutura de apoio ao turismo, assim como todo o processo de avaliação e hierarquização dos mesmos.

2. Dimensionamento da atual demanda turística, para embasar prognósticos futuros para a região.

3. Levantamento e análise da concorrência local no âmbito da atividade turística, envolvendo análise dos produtos oferecidos pelas diversas empresas prestadores de serviços turísticos e agentes de mercado atuando na região; grau de aceitação desses produtos no mercado; aumento da arrecadação de impostos e carga tributária; os reflexos na balança comercial da região, entre outros.

4. Levantamento e determinação da capacidade de suporte da região turística, com o objetivo de futura avaliação, tanto dos impactos positivos como dos negativos da atividade turística, mediante aplicação de indicadores específicos. O estudo da capacidade de suporte deve considerar também os impactos ambientais decorrentes da 
atividade turística numa determinada área, incluindo, ainda, os impactos culturais, sociais e econômicos.

5. Caracterização sócio-econômico-cultural da comunidade regional, incluindo sua opinião, o grau de envolvimento e integração da mesma no processo de regionalização.

6. Levantamento dos pontos fortes e fracos, oportunidades e ameaças da atividade turística na região, associados ao processo de regionalização do turismo.

Fase 2: Elaboração do Planejamento Estratégico

As informações obtidas por meio da etapa anterior embasarão as discussões e tomadas de decisão capazes de formatar a visão de futuro correspondente ao desenvolvimento do turismo pretendido para a região em foco. Esse prognóstico fará parte do Plano Estratégico de Desenvolvimento do Turismo Regional. Nessa fase são identificadas as prioridades de objetivos, a partir de critérios preestabelecidos.

O Plano Estratégico de Desenvolvimento do Turismo Regional apresenta toda a estratégia para promover, qualificar e/ou fortalecer a atividade turística. O foco é mantido na identidade regional, seus segmentos e características. Deve perseguir também a eficiência e eficácia econômica, justiça social e harmonia ambiental, considerando as necessidades da população local, sem, contudo, desrespeitar as necessidades das gerações futuras.

Além do diagnóstico apresentado, o Plano Estratégico deve conter:

a) O objetivo geral que se pretende alcançar e que deverá orientar a estratégia a ser adotada na região turística que vai variar de acordo com as características e o estágio de desenvolvimento do turismo na região. Além disso, deve, também, nortear as ações governamentais e da iniciativa privada, para que sejam viabilizados os novos produtos turísticos criados dentro do foco da regionalização do turismo e de acordo com as diretrizes de sustentabilidade traçadas pelo Programa de Regionalização do Turismo Roteiros do Brasil.

b) Os objetivos específicos, representados pelos enunciados dos Projetos Específicos a serem elaborados na fase seguinte ao planejamento estratégico.

c) As linhas de ação, que são os meios para o alcance dos objetivos propostos.

d) As metas a serem alcançadas no decorrer do Plano Estratégico de Desenvolvimento do Turismo Regional.

e) Os indicadores de impacto e benefício, que permitirão o acompanhamento, o monitoramento e a avaliação do Plano Estratégico de Desenvolvimento do Turismo Regional, como base nos ajustes necessários. 


\section{CENÁRIOS PROSPECTIVOS PARA O TURISMO}

\subsection{Proposta de um Referencial Metodológico Teórico para Construção de Cenários Prospectivos Aplicável ao Turismo}

Após análise da metodologia adotada pelo Ministério do Turismo para elaboração de um planejamento estratégico que visa o desenvolvimento do turismo regional verifica-se a abordagem a partir de previsões que tem o objetivo explícito de acertar, com maior probabilidade possível, a(s) variável (eis) em questão. A proposta aqui apresentada demonstra a necessidade de investir em projetos analisados de forma exploratória, ou seja, entender a realidade local e buscar futuros possíveis e prováveis com o objetivo de alcançar um desenvolvimento sustentável no setor turístico, bem como atingir metas que sejam plausíveis e alcançáveis, sem que seja assumida qualquer opção ou preferência por um dos futuros configurados.

Desta forma o modelo teórico é a base para essa análise e formulação consistente do movimento futuro, interpretando as relações de causa e efeito de múltiplas variáveis e de comportamentos imponderáveis com base no conhecimento científico para estruturar as informações e compreender a lógica e a dinâmica da realidade, contando com um referencial analítico ou modelo de interpretação teórico do objeto ou do sistema. No delineamento desse modelo teórico é utilizado um conjunto de técnicas que servem para realizar os diversos estágios do processo de construção utilizadas, consensualmente, pelos autores que representam hoje referência bibliográfica ao tema citados na seção 3 deste trabalho.

Dada a importância da aplicação dessas técnicas ao setor do turismo, que possibilitará a tomada de decisões por parte dos gestores do setor, essa metodologia adota a caracterização dos cenários prospectivos para o turismo como exploratórios, por possuir conteúdo, essencialmente, técnico com tratamento racional das possibilidades para descrição dos cenários futuros. Esta proposta visa contribuir para a construção do Plano Estratégico de Desenvolvimento Regional do Turismo a partir do estudo sistemático das mais diversas variáveis e atores que envolvem o sistema, para só então, definir metas alcançáveis e aplicação de recursos que gerem um desenvolvimento sustentável.

Para tanto este trabalho sugere a utilização de uma análise estrutural do contexto regional por meio do método indutivo que parte do objeto para identificar os fatores externos 
que podem determinar o seu futuro, demandando uma formulação prévia dos cenários do contexto, na medida em que tais condicionantes podem ter diferentes comportamentos. A figura 8 abaixo demonstra as etapas do método proposto para geração de cenários no setor turístico:

\section{Figura 8 - Etapas do Método Proposto para Geração de Cenários no Turismo}

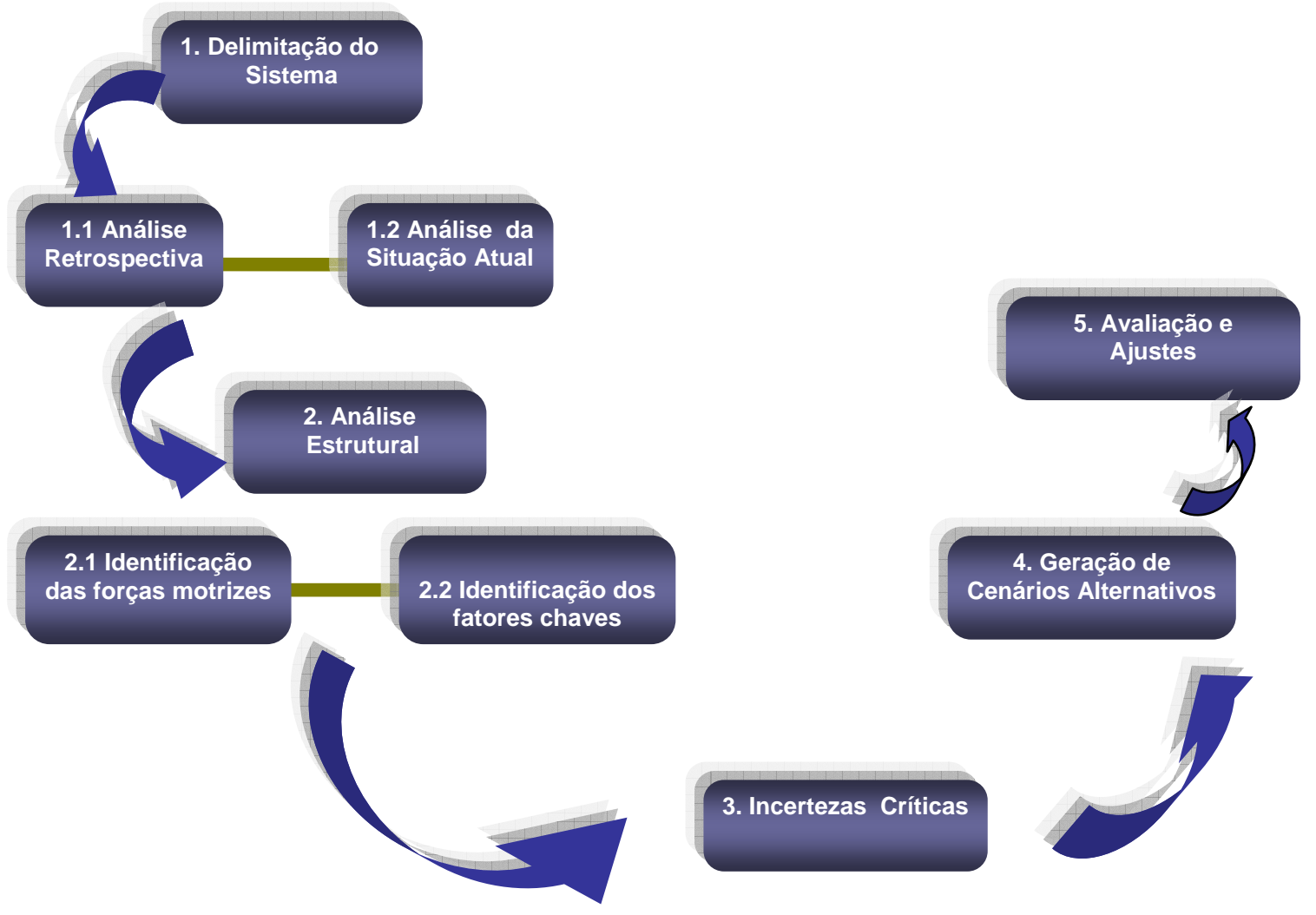

Fonte: Elaborado pela autora

A Delimitação do Sistema, do Horizonte e do Ambiente constituiu a primeira etapa, onde se defini a abrangência do estudo, especifica-se o sistema e realiza o estudo do ambiente interno e externo com identificação preliminar das variáveis chaves permitindo realizar a Análise Retrospectiva e da Situação Atual que visa entender os mecanismos e atores determinantes de sua evolução passada e entender a evolução recente do sistema a fim de levantar as tendências dos processos, em curso, que sinalizam os caminhos futuros.

A segunda etapa, denominada de Análise Estrutural, consiste na elaboração de uma lista, mais completa possível, das variáveis relevantes do sistema e de seus principais atores, considerada neste trabalho a de maior importância no processo, pois contribui para uma reflexão sobre o sistema e sobre as escolhas estratégicas para definição dos cenários. No 
primeiro momento esta técnica permite a classificação das variáveis em relação a um certo número de parâmetros fundamentais para caracterizar o seu papel no sistema e pondo assim em evidência uma hierarquia de variáveis, ou seja, as variáveis que expressam sinteticamente a realidade, em seguida se realiza o estudo das relações de causalidade entre elas, gerando a matriz de análise estrutural variável x variável, conforme demonstra a figura 9. Para construir essa matriz de influências os seguintes passos devem ser seguidos:

1. Montar uma matriz quadrada variável-variável com todas as variáveis;

2. Identificar a influência de cada variável sobre cada uma das outras através da atribuição de peso numérico (medida do grau da influência);

3. Somar as linhas e colunas da matriz:

$\checkmark$ A soma das linhas forma uma hierarquia que indica o grau de influência de cada variável sobre o conjunto;

$\checkmark$ A soma das colunas forma uma hierarquia que indica o grau de dependência de cada variável do conjunto;

4. Selecionar as variáveis de maior influência (hierarquia da influência)

Figura 9 - Matriz de Análise Estrutural - variável/variável

\begin{tabular}{|c|l|l|l|l|l|l|l|}
\hline$\underset{\text { VARÍ́VEL }}{\stackrel{\text { VARIÁVEL }}{\longrightarrow}}$ & A & B & C & D & $\ldots \ldots \ldots .$. & N & $\begin{array}{c}\text { Poder de } \\
\text { Influência }\end{array}$ \\
\hline A & & & & & & & \\
\hline B & & & & & & & \\
\hline C & & & & & & & \\
\hline D & & & & & & & \\
\hline$\ldots . .$. & & & & & & & \\
\hline N & & & & & & & \\
\hline $\begin{array}{c}\Sigma \text { Grau de } \\
\text { Dependência }\end{array}$ & & & & & & & \\
\hline
\end{tabular}

Fonte: Godet, 1995; Macroplan, 1996.

A partir dessa estrutura torna-se possível gerar o diagrama motrocidade-dependência conforme figura 10, distribuindo as variáveis em um sistema de coordenadas dividido em quatro blocos (quadrantes do diagrama): as variáveis explicativas (alta influência e baixa dependência) que condicionam o restante do sistema; as variáveis de ligação (alta influência e alta dependência) que fazem a ligação entre as variáveis explicativas e as de resultados; as variáveis de resultado (baixa influência e alta dependência) onde seu comportamento é 
explicado pelas variáveis explicativas ou de ligação; e as variáveis autônomas (baixa influência e baixa dependência) que não constituem determinantes do futuro, podendo ser excluídas da análise.

Figura 10 - Diagrama motrocidade-dependência

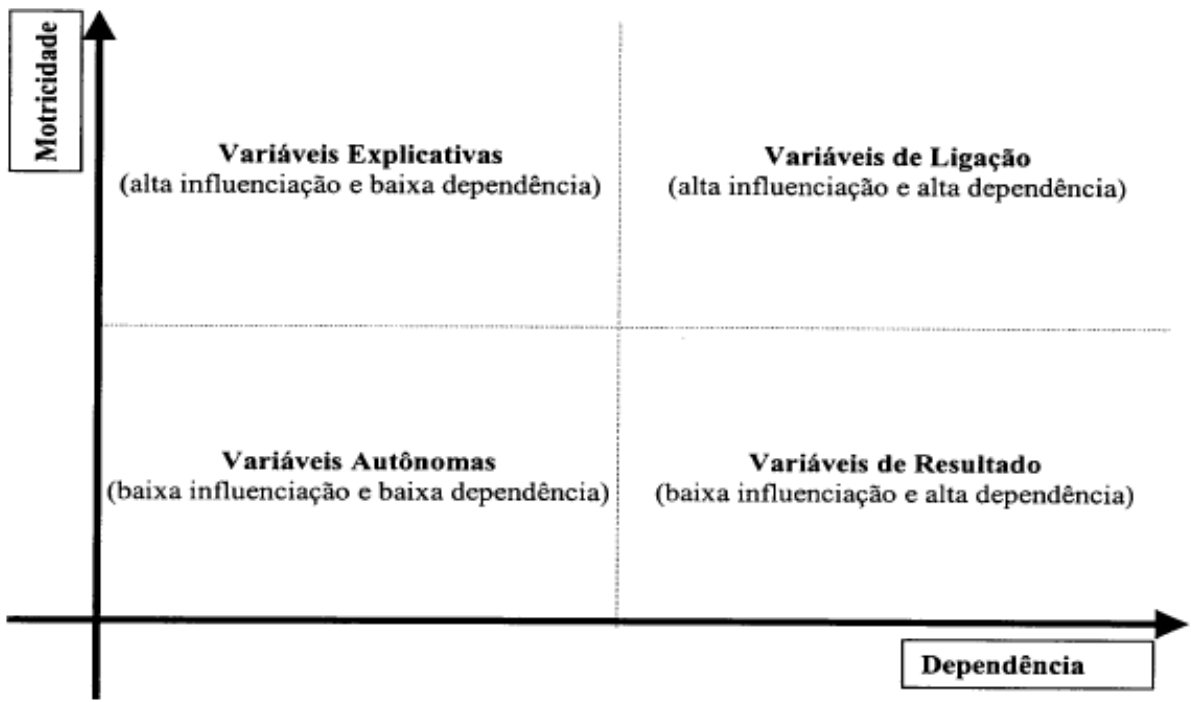

Fonte: Godet, 1985.

O próximo passo da Análise Estrutural é a análise das estratégias dos atores, identificando seus projetos e motivações, seus meios de ação e seus desafios estratégicos. A identificação dos atores mais influentes é realizada mediante o cruzamento atores $\mathrm{x}$ variáveis conforme apresentado na figura 11, que permite entender a relação e grau de influência (motrocidade) de cada um e assim identificar os atores que precisam ser estudados mais a fundo.

Figura 11 - Matriz ator/variável

\begin{tabular}{|c|l|l|l|l|l|l|l|}
\hline$\underset{\text { Potência das }}{\text { Variáveis }}$ & VARIÁVEEL & B & C & D & $\cdots \ldots . .$. & N & $\begin{array}{c}\text { E Poder de } \\
\text { Influenciacão } \\
\text { dos Atores }\end{array}$ \\
\hline ATOR & & & & & & & \\
\hline I & & & & & & & \\
\hline II & & & & & & & \\
\hline III & & & & & & & \\
\hline IV & & & & & & & \\
\hline$\ldots \ldots .$. & & & & & & & \\
\hline M & & & & & & & \\
\hline
\end{tabular}

Fonte: Godet, 1985; Macroplan, 1996 
É neste momento que se torna possível identificar um dos seis principais componentes de um cenário: a cena, que descreve como estão organizados ou vinculados entre si os atores e as variáveis em um determinado instante de tempo.

A análise estrutural é um instrumento de auxílio à decisão. Não pretende descrever com precisão o funcionamento do sistema e sim evidenciar as grandes linhas de sua organização. De acordo com Godet (1993) é preciso ter em mente os limites da análise estrutural para a utilização dos resultados: o primeiro limite vem do caráter subjetivo da lista de variáveis, e o segundo está na subjetividade do preenchimento da matriz de relações.

Com base nessas análises, inicia-se a terceira etapa responsável pela Seleção das Condicionantes do Futuro endógenos e exógenos ao sistema. São os processos sistêmicos, contínuos ou pontuais, de natureza social, cultural, econômica, política, ambiental, tecnológica (etc) que têm influência relevante na trajetória futura do objeto de cenarização, ou seja, fenômenos ou fatores que definirão futuros alternativos, tais como as tendências de peso, os fatos portadores de futuro, os fatores predeterminados, as variantes e as alianças existentes entre os atores. Neste momento utiliza-se a técnica Matriz de Impacto x Incerteza que permitirá a análise das variáveis hierarquizadas seguindo dois critérios simultâneos: o seu grau de impacto sobre o sistema (o estado/região turística) e o seu nível de incerteza. Para tanto e de forma muito simples atribui-se para classificação quanto ao impacto e incerteza a tipologia "baixo”, “médio”, e "alto” gerando-se a matriz conforme figura 12. Assim quanto maior for o impacto e o nível de incerteza de uma dada variável maior a utilidade de considerá-la na geração de cenários, pois se constituem em incertezas críticas.

Figura 12 - Matriz impacto/incerteza

\begin{tabular}{|c|l|l|l|}
\hline Impacto & \multicolumn{1}{|c|}{ Alta } & \multicolumn{1}{|c|}{ Média } & \multicolumn{1}{|c|}{ Baixa } \\
\hline Alto & $\begin{array}{l}\text { Descrição dos eventos com } \\
\text { alto grau de incerteza e alto } \\
\text { impacto }\end{array}$ & $\begin{array}{l}\text { Descrição dos eventos com } \\
\text { médio grau de incerteza e alto } \\
\text { impacto }\end{array}$ & $\begin{array}{l}\text { Descriç̧áo dos eventos com } \\
\text { baixo grau de incerteza e alto } \\
\text { impacto }\end{array}$ \\
\hline Médio & $\begin{array}{l}\text { Descrição dos eventos com alto } \\
\text { grau de incerteza e médio } \\
\text { impacto }\end{array}$ & $\begin{array}{l}\text { Descrição dos eventos com } \\
\text { médio grau de incerteza e } \\
\text { médio impacto }\end{array}$ & $\begin{array}{l}\text { Descrição dos eventos com } \\
\text { baixo grau de incerteza e médio } \\
\text { impacto }\end{array}$ \\
\hline Baixo & $\begin{array}{l}\text { Descrição dos eventos com alto } \\
\text { grau de incerteza e baixo } \\
\text { impacto }\end{array}$ & $\begin{array}{l}\text { Descrição dos eventos com } \\
\text { médio grau de incerteza e baixo } \\
\text { impacto }\end{array}$ & $\begin{array}{l}\text { Descrição dos eventos com } \\
\text { baixo grau de incerteza e baixo } \\
\text { impacto }\end{array}$ \\
\hline
\end{tabular}

Fonte: Buarque, 2003 
A quarta etapa é responsável pela Geração de Cenários Alternativos, que decorre da combinação consistente das diferentes hipóteses sobre o comportamento futuro das incertezas críticas. Esta combinação e a análise da sua consistência podem ser feitas com o apoio da Matriz de Investigação Morfológica, na qual são ordenadas, pela abrangência, permitindo construir os caminhos de articulação de estados das incertezas, formando quadros futuros diferenciados do objeto em análise. Os estados futuros de cada incerteza (hipóteses) estão apresentados na matriz nas linhas correspondentes a cada uma delas, conforme figura 13 a seguir: 
Figura 13 - Matriz de Investigação Morfológica

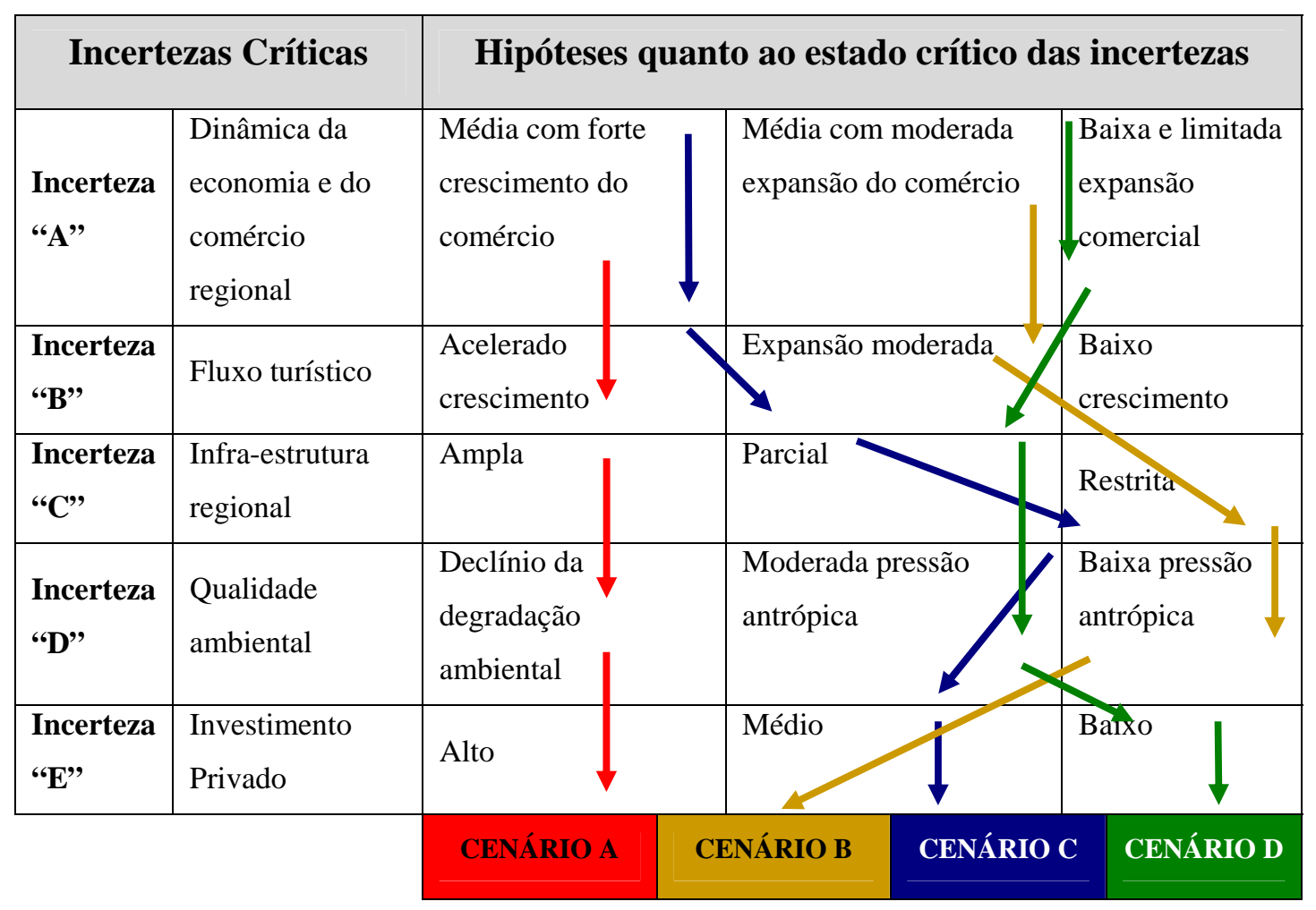

Fonte: Elaborado pela autora

È importante examinar cada incerteza e definir que estados alternativos plausíveis ela pode assumir para então efetuar as combinações dos estados alternativos das incertezas, considerando os critérios de consistência. Cada incerteza pode assumir várias hipóteses. Haverá, portanto, tantos cenários possíveis quantas forem às combinações de hipóteses. O conjunto destas combinações representa o campo de possibilidades ou campo morfológico.

Antes da finalização do relatório com a descrição dos possíveis cenários do objeto em estudo, esses são submetidos ao processo avaliação e ajustes a fim de assegurar a coerência e consistência e emissão do relatório final contendo opções estratégicas. Para uma adequada avaliação da consistência interna do cenário, é importante verificar os seguintes pontos:

- A seqüência dos eventos está correta?

- Os números estão corretos e consistentes com as hipóteses?

- Os prazos e datas de eventos críticos estão compatíveis?

- As hipóteses estão consistentes entre si?

- Há coerência entre os diversos níveis de cenários?

- As cenas intermediárias nos diversos níveis de cenários estão consistentes? 
O Teste de robustez consiste na verificação da viabilidade do cenário segundo critérios explícitos:

- Viabilidade: é viável do ponto de vista político, econômico, técnico, social e ecológico?

- Aceitabilidade: apresenta razoável grau de aceitação técnica e ideológica? É sustentável a médio e longo prazos?

- Conformidade: apresenta nível razoável de conformidade ética, legal e institucional?

- Comunicabilidade: apresenta adequado nível de objetividade, clareza e concisão? 


\section{CONCLUSÃO}

A técnica de cenários prospectivos auxilia as organizações na identificação das diversas possibilidades de situações futuras, respaldando o processo de tomada de decisões e permitindo a formulação de planejamento futuros com um menor número de incertezas.

Tal abordagem permite entender a importância da análise e estudo das mais diversas variáveis endógenas e exógenas do ambiente em que as organizações estão inseridas, bem como o grau de impacto dessas variáveis e as incertezas geradas durante o desenvolvimento do planejamento estratégico para implementação de estratégias com vistas ao crescimento nos diferentes setores da economia.

É importante ressalta que esse trabalho visa agregar valor ao planejamento estratégico de desenvolvimento regional do turismo, uma vez que, a utilização deste referencial teórico contribuirá para um melhor entendimento das mais diversas variáveis e atores que fazem parte do setor, identificadas durante a análise morfológica e tratadas de forma diferenciada dado o grau de incertezas que as mesmas geram no futuro desejado.

De forma criteriosa o entendimento das hipóteses que essas incertezas críticas podem gerar permitira às organizações visualizar os cenários com maior consistência e então garantir investimentos com alto grau de retorno para o destino turístico, a sociedade e a economia local.

Destaca-se ainda que as técnicas prospectivas encontram valores que permitem a construção de cenários com uma visão a médio e longo prazos. Esta é uma contribuição importante ao estudo e desenvolvimento no setor turístico, cujas características de subjetividade deste nem sempre permitem minimizar os riscos dos altos investimentos exigidos no setor.

A outra contribuição é a consistência com que os meios organizacionais podem operar, uma vez que este método adota princípios que se voltam para sistemas, ambientes, e forças que dificultam o avanço do setor, por meio da identificação das áreas de incertezas, dos níveis de competitividade, e do diagnóstico estratégico, além de auxiliar na avaliação e interpretação de diversas alternativas.

Tal processo de identificação, de busca da análise e da interpretação da informação, permite a transformação e desenvolvimento das organizações que incorporam tais conceitos e os praticam sistematicamente. Esta visão pode ser expandida ao planejamento de políticas governamentais voltadas para o turismo brasileiro, que tem como missão o desenvolvimento sustentável do setor. 
Por fim, há um ganho expressivo nas áreas da estratégia, da aprendizagem e da inteligência competitiva, quando os métodos e técnicas se comungam na construção de cenários e na contribuição à efetividade dos objetivos maiores de uma organização.

Conclui-se, portanto, que o modelo apresentado contribuirá para identificar e priorizar atores, agentes e parcerias estratégicas voltados ao desenvolvimento sustentado dos diversos setores, além de promover a difusão do conhecimento. 


\section{BIBLIOGRAFIA}

BETHLEM, Agrícola. Estratégia empresarial: conceitos, processos e administração estratégica. 4. ed. São Paulo: Atlas, 2002.

BUARQUE. Sergio C. Metodologia e Técnicas de Construção de Cenários Globais e Regionais - Texto para Discussão IPEA - Brasília, n: 939, fevereiro de 2003.

\section{ELETRONORTE/PPM - CLÁUDIO PORTO e CONSULTORES ASSOCIADOS.} Amazônia: cenário sócio-econômico e projeção da demanda de energia elétrica no horizonte 2010. Brasília, junho de 1988, mimeo.

GUIMARÃES, Aluísio e PORTO, Cláudio. Macroplan - Prospectiva, Estratégia \& Gestão. Elementos Básicos da Gestão e o Contexto da Ação Gerencial, 2005. Disponível em: <http://www.macroplam.com.br>.Acesso em:15 dez 2007.

GOMES de SOUZA, O. C.; GOMES de SOUZA, I.; ABREU SILVA, A. de. Manual de Técnicas de Previsão (versão preliminar). Rio de Janeiro: Secretaria Geral de Planejamento/ Instituto Universidade de Pesquisa do Rio de Janeiro, 1976, mimeo.

JAGUARIBE, H. Brasil 2000. Rio de Janeiro: Paz e Terra, 1989a.

MARCIAL, Eliane Coutinho e Raul José dos Santos GRUMBACH. Cenários Prospectivos: Como Construir um Futuro Melhor. Rio de Janeiro: Editora FGV, 2006 4. ed, Capítulos 3, 4 e 5 - (Coleção FGV Negócios)

MONTGOMERY, C. e PORTER, M. Estratégia: a busca da vantagem competitiva. Rio de Janeiro: Campus, 1998.

OLIVEIRA, Djalma de Pinho Rebouças de. Estratégia Empresarial e Vantagem Competitiva: como estabelecer, implementar e avaliar. São Paulo: Atlas, 2007.

PORTER, Michael E. Estratégia Competitiva: técnicas para análise de indústrias e da concorrência. Rio de Janeiro: Campus, 1992. 
RIBEIRO, Marcelo de Paula Mascarenhas. Planejando por cenários: uma ferramenta para a era do conhecimento. Revista Científica das Faculdades SPEI. p. 20-26. Ano 2, n.2, junho 2001.

SCHWARTZ, Peter. A arte da visão de longo prazo: planejando o futuro em um mundo de incertezas. São Paulo: Best Seller, 2000.

SEBRAE. Cenários do Ambiente de Negócios da Pequena e Micro Empresa de Pernambuco (versão executiva). Recife: dezembro de 1996, mimeo.

SENAI/MACROPLAN. Macrocenários mundiais e nacionais com focalização no Nordeste e impactos sobre o sistema de ensino superior e Senai - Horizonte 1997-2010. Rio de Janeiro, março de 1997, mimeo.

SEPLAN/PR-PROJETO ARIDAS. Nordeste: uma estratégia de desenvolvimento sustentável (versão preliminar). Brasília, 1994, mimeo.

SUDAM/BASA/SUFRAMA. Macrocenários da Amazônia - cenários alternativos e cenários normativos da Amazônia no horizonte 2010. Relatório Final (1a versão). Belém, julho de 1990, mimeo. 